\title{
Review of external convective heat transfer coefficient models in building energy simulation programs: implementation and uncertainty
}

\author{
M. Mirsadeghi, D. Cóstola* , B. Blocken, J.L.M. Hensen \\ Building Physics and Services, Eindhoven University of Technology, the Netherlands
}

\begin{abstract}
Convective heat transfer coefficients for external building surfaces $\left(h_{c, \text { ext }}\right)$ are essential in building energy simulation (BES) to calculate convective heat gains and losses from building facades and roofs to the environment. These coefficients are complex functions of, among other factors, building geometry, building surroundings, building facade roughness, local air flow patterns and temperature differences. Previous research on $h_{c, \text { ext }}$ has led to a number of empirical models, many of which are implemented in BES programs. This paper first provides an extensive overview of such models for $h_{c, e x t}$ calculation implemented in BES programs together with the corresponding assumptions. Next, the factors taken into account by each model are listed, in order to clarify model capabilities and deficiencies. Finally, the uncertainty related to the use of these models is discussed by means of a case study, where the use of different models shows deviations up to $\pm 30 \%$ in the yearly cooling energy demand (in relation to the average result) and $\pm 14 \%$ in the hourly peak cooling energy demand of an isolated, well-insulated building, while deviations in yearly heating energy demand are around $\pm 6 \%$. The paper concludes that each model has a specific range of application, which is identified in this review paper. It also concludes that there is considerable uncertainty in the prediction of $h_{c, \text { ext }}$, which can be transferred to the BES results. This large uncertainty highlights the importance of using an appropriate convection model for simulations of a specific building, certainly for calculating cooling demands and related important performance indicators such as indoor temperatures, indoor relatively humidity, thermal comfort, etc.
\end{abstract}

Keywords: convective heat transfer coefficient; wind-induced heat transfer; buoyancy; heat, air and moisture transfer (HAM); building envelope

* Corresponding author: D. Costola, Building Physics and Services, Eindhoven University of Technology,

P.O. box 513, $5600 \mathrm{MB}$, Eindhoven, the Netherlands.

Tel.: +31 (0)40 247 2273, Fax +31 (0)40 243 8595, E-mail: d.costola@ tue.nl 


\section{Introduction}

Building energy simulation (BES) programs are important tools in building design and operation [1-4]. This importance is illustrated by the large variety of BES programs that have been developed during the past six decades [5]. These programs combine many first-principle and empirical models to describe relevant energy flow processes in buildings [6]. This paper focuses on one of these processes; the convective heat exchange between the exterior building surfaces and the external environment. This heat exchange can be 3 to 4 times higher than long-wave radiative heat exchange $[7,8]$. Convective heat exchange for external building surfaces is usually calculated based on convective heat transfer coefficients $\left(h_{c, e x t}\right)$. The knowledge of these coefficients is crucial for an accurate evaluation of the heat removal from building envelopes, solar collectors, solar chimneys, etc [8]. They can also strongly influence the inward-flowing fraction of solar radiation which appears as cooling load in buildings [9]. Apart from energy demand calculations, $h_{c, \text { ext }}$ is also important to provide accurate estimates of exterior surface temperatures in BES programs, which in turn provide information on nocturnal condensation risk and mould growth on well-insulated facade systems, etc [10]. The importance of $h_{c, \text { ext }}$ is not only recognized in BES programs, but also in heat, air and moisture (HAM) transfer studies in building research and engineering [11-13].

The convective heat transfer coefficient is defined as:

$$
h_{c, e x t}=\frac{q_{c}}{T_{s}-T_{a}} \quad\left(\mathrm{~W} / \mathrm{m}^{2} . \mathrm{K}\right)
$$

where $\mathrm{q}_{\mathrm{c}}$ is the convective heat flux, $\mathrm{T}_{\mathrm{s}}$ is the surface temperature and $\mathrm{T}_{\mathrm{a}}$ is the air temperature [14].

The convective heat transfer coefficient is influenced by several factors, such as the geometry of the building and building surroundings, the position at the building envelope, the building surface roughness, wind speed, wind direction, local airflow patterns and surface to air temperature differences $[11,15]$. In urban areas, local airflow patterns around a building strongly depend on the arrangement and geometry of neighbouring buildings [16-24] which strongly influence $h_{c, \text { ext }}$. Terrain type influences the mean wind speed and turbulence intensity profiles [18, 25-27], which also influence $h_{c, \text { ext }}[11]$.

There are different methods to obtain values for $h_{c, e x t}$, which can be categorized in analytical, numerical and experimental methods [6]. Analytical methods are only applicable for some specific flow regimes and simple geometries, e.g. flat plates and cylinders $[28,29]$. Numerical methods, namely Computational Fluid Dynamics (CFD), are powerful tools to calculate $h_{c, \text { ext }}[11,30-32]$. Recently, CFD has been applied and validated to calculate $h_{c, \text { ext }}$ for windward facades, however these simulations demand large computational resources and the accuracy of results for leeward facades and roofs still demands improvements [11, 30-33]. Experimental methods, both in reduced-scale and full-scale tests, are currently still the main source of $h_{c, e x t}$ data.

Considering the complexity involved in obtaining $h_{c, \text { ext }}$ data, previous experimental research on this topic has led to a large number of empirical models [8], many of which are implemented in BES. However, to the knowledge of the authors, there is no overview of the models implemented in BES programs and the assumptions adopted in each of these implementations. Moreover, the range of application of each model is also not clear, and neither is the uncertainty of the results obtained with these different models. These are the issues addressed in this paper, which is organised as follows. Section 2 describes the BES programs analysed in the present research, and it provides an thorough overview of existing models for $h_{c, \text { ext }}$ calculation implemented in these programs. This section condenses and organises a large amount of information collected from BES programs (source codes and documentation) as well as from numerous books and articles published in the last 88 years and used as reference in BES programs. Therefore, Section 2 is primarily an informative section, representing more than half of the paper. Readers with less interest in the background of each model and its implementation will find in Section 3 a straightforward comparison of the models (based on findings of Section 2). Section 3 discusses the factors taken into account by each model, clarifying their capabilities and deficiencies and allowing the identification of their range of application. Section 3 also compares the $h_{c, \text { ext }}$ results obtained using different models, in order to show the uncertainty in their predictions. Section 4 discusses the impact of using different $h_{c, \text { ext }}$ models on the results of energy demand calculation for a simple isolated, well-insulated building model. Section 5 provides a discussion about additional issues in the models analysed in the current research. Section 6 summarizes the main the conclusions of this paper.

\section{Overview of $\boldsymbol{h}_{c, \text { ext }}$ models in BES programs}

To support the review, first of all an attempt was made to create a list of BES programs commonly used in research and industry. For this list, the same technique as used by Cóstola et al. [34] was adopted and the selection of BES programs was mainly influenced by one of the latest comparative surveys by Crawley et al. [5]. 
The BES programs chosen for this survey were: ESP-r [35], EnergyPlus [36], IES [37], IDA [38], TAS [39], TRNSYS [40] and SUNREL [41].

For these programs, we performed an investigation of the implemented $\mathrm{h}_{\mathrm{c}, \mathrm{ext}}$, based on the documentation of the programs and on their codes, in cases where the programs are open source. The models implemented in each BES program, as well as some simplified approaches to describe $h_{c, \text { ext }}$, are presented in Table 1, in which some patterns can be observed. The model by McAdams [42] is the most used model, being utilized by 3 out of 7 programs. Most of the models (14 out of 17) are implemented in only one program, which seems to indicate that there is no consensus in BES programs about the models to be adopted. In fact, it is possible to identify 3 groups of BES programs based on the number and type of models implemented. Group 1 is composed of programs which have several models implemented, such as ESP-r (12 out of 17 models) and EnergyPlus (6 out of 17). These programs provide a large range of options for the user, who can choose the most appropriate model for his/her specific problem. However, the program documentation usually does not provide guidelines about the applicability of each model. Group 2 is composed by programs which rely on a single model to calculate $h_{c, \text { ext }}$, such as IES, IDA and TAS. In these programs, the models which are implemented are all based on the experiments carried out in a wind tunnel by Jürges in 1924 [43]. Group 3 is composed by programs where no empirical model is implemented and where a fixed value for $h_{c, e x t}$, is adopted, such as in TRNSYS and SUNREL. The approach adopted by group 3 might look like a major simplification, nevertheless these two programs comply with the BESTEST [44]. It indicates that this simplification might be acceptable under specific conditions of weather, building characteristics and performance indicator. The models in Table 1 can be divided in 5 categories. This classification is mainly based on the nature of the experiment (reduced-scale or full-scale) underlying the model and on the definition of reference wind speed used in the experiments or which led to the development of the $h_{c, \text { ext }}$ models. These definitions, which are based on the positions of the wind speed sensor, have a large impact on the model results. Figure 1 schematically displays five often used definitions for the wind speed:

- Free stream wind speed $\left(V_{f}\right)$ : This is the wind speed far away from any object or physical boundaries, where the flow is not disturbed by any object or physical boundary (Figure 1-a).

- $\quad$ Roof wind speed $\left(V_{R}\right)$ : This is the wind speed measured at height H' from the roof surface (Figure 1-b).

- Local wind speed $\left(V_{l o c}\right)$ : This is the wind speed measured at a certain distance $\mathrm{d}$ from the building facade and at a certain height $(\mathrm{H})$ from the ground (Figure 1-b).

- Wind speed measured at height $\mathrm{z}\left(V_{z}\right)$ : This is the wind speed measured at height $\mathrm{z}$ above ground level in the upstream undisturbed wind flow (Figure 1-b).

- Wind speed measured at $10 \mathrm{~m}\left(V_{10}\right)$ : This is the wind speed measured at $10 \mathrm{~m}$ above the ground level in the upstream undisturbed wind flow (Figure 1-b). This is the only type of wind speed data available in standard BES program weather files. This implies that for use in BES programs, $V_{f}, V_{R}$ and $V_{l o c}$ must be estimated based on $V_{10}$.

Note that there is no consensus on the definition of reference wind speed. This lack of uniformity between the models leads to a number of inconsistencies in their implementation in BES programs. The following subsections briefly describe the $\mathrm{h}_{\mathrm{c}, \mathrm{ext}}$ models presented in Table 1 , addressing their main factors and discussing the assumptions and inconsistencies in their implementation in different BES programs. All models are presented in SI units. Note that the amount of information available for each model is different, which is reflected in the descriptions provided below.

\subsection{Model by McAdams [42]}

This model is based on the wind tunnel experiments reported by Jürges [43], obtained using a vertical square copper plate $\left(1.64 \times 1.64 \mathrm{ft}^{2}\right.$, i.e. $\left.0.5 \times 0.5 \mathrm{~m}^{2}\right)$ in a uniform air flow parallel to the plate. McAdams [42] reports the following expression of the model (adapted for SI units [6]):

$$
h_{c, e x t}=5.678\left[m+n\left(\frac{V_{f}}{0.3048}\right)^{p}\right]
$$

where $m, n, p$ are roughness parameters for smooth and rough surfaces given in Table 2. Note that the parameters for both types of roughness are quite similar, and that $h_{c, \text { ext }}$ for rough surfaces is only about 6 to $10 \%$ higher than for smooth surfaces, for wind speed from 0 to $15 \mathrm{~m} / \mathrm{s}$ (the larger difference, i.e. $10 \%$, occurs at low wind speeds). Moreover, the criterion that should be used to classify surfaces as either smooth or rough is not clear. It should be noted that in this model, as in most others, radiative heat transfer is not taken into account. While it seems logical that $h_{c, \text { ext }}$ models do not include radiative heat transfer, a few implementations in BES programs do combine convective and radiative transfer coefficients. In addition, the measurements underlying the $h_{c, \text { ext }}$ also included radiative heat transfer. A detailed discussion on this item is provided in section 5.5. In the present 
section, the approach adopted by each model regarding the radiative component is included in the description of every model in this section for completeness. Ref. [42], which is a heat transfer text book, does not provide information about the following factors that influence $h_{c, \text { ext }}$ : building type (high, medium or low-rise), surface orientation (windward, leeward, roof), sheltering effect by other buildings, and terrain types. In spite of the absence of this information, this is the most implemented model in the selected BES programs: it is implemented in ESP-r, IES and IDA. The assumptions underlying these implementations are described in the following subsections.

\subsubsection{Implementation in ESP-r}

The model by McAdams is the default model for $h_{c, \text { ext }}$ in ESP-r, however in the ESP-r source code the implementation of this model is different from Eq. (2) [42]. ESP-r uses the following linear expression:

$$
h_{c, e x t}=3 V_{l o c}+2.8
$$

Eq. (2) can indeed be linearized leading to Eq. (4), with errors up to $3 \%$ for $V_{\text {loc }}$ up to $15 \mathrm{~m} / \mathrm{s}$ :

$$
h_{c, e x t}= \begin{cases}3.8 V_{l o c}+7.4 & \text { for rough surfaces } \\ 3.6 V_{l o c}+6.5 & \text { for smooth surfaces }\end{cases}
$$

These linearized equations do not resemble Eq. (3), so the origin of Eq. (3) remains unclear. The use of $V_{f}$ in Eq. (2) requires some adaptation in the implementation because, as mentioned earlier, BES programs only have $V_{10}$ data available. In Eq. (3), ESP-r assumes $V_{f}=V_{l o c}$, and uses an additional model to estimate $V_{l o c}$ from $V_{l 0}$, see Eq. (5) to (8). In these equations, $\phi$ is the vertical angle between the ground plane and the surface plane (see Figure 1) and $\theta$ is the horizontal wind attack angle, i.e. the angle between the surface normal vector and the wind direction. The source of Eqs. (5) to (8) could not be found in the ESP-r documentation.

Eq. (5) is applied for horizontal surfaces and surfaces with slope angle $(\phi)$ in the range: $0^{\circ} \leq \phi \leq 45^{\circ}$ or $135^{\circ}$ $<\phi \leq 180^{\circ}$.

$$
V_{l o c}=V_{10}
$$

Eqs. (6) - (8) are applied for surfaces with slope angle between: $45^{\circ}<\phi \leq 135^{\circ}$, which includes vertical surfaces:

Windward surface with $0^{\circ}<\theta \leq 10^{\circ}$ :

$$
V_{\text {loc }} \cong\left\{\begin{array}{lll}
0.5 V_{10} & \text { for } & V_{10} \leq 1 \mathrm{~m} / \mathrm{s} \\
0.5 \mathrm{~m} / \mathrm{s} & \text { for } & 1<V_{10} \leq 2 \mathrm{~m} / \mathrm{s} \\
0.25 V_{10} & \text { else } &
\end{array}\right.
$$

Windward surface with $10^{\circ}<\theta \leq 90^{\circ}$ :

$$
V_{l o c}=V_{10} \sin \theta
$$

Leeward surface $\left(90^{\circ}<\theta \leq 180^{\circ}\right)$ :

$$
V_{l o c}=0.25 V_{10} \sin \theta
$$

In two aspects, this implementation clearly avoids overestimations of $h_{c, e x t}$. Firstly, $V_{l o c}$ is assumed to be always smaller or equal to $V_{10}$, which might not be the case, for example, for high-rise buildings $[16,18,22,46]$. Secondly, the coefficients adopted by ESP-r in Eq. (3) are smaller than the ones in the linearized model (Eq. (4)), which consequently gives results 30 to $55 \%$ lower than the original model. Combined, these two aspects can provide predictions of $h_{c, \text { ext }}$ on facades up to $78 \%$ smaller than the original model (Eq. 2)). As in the original model, other factors such as building type (high, medium or low-rise), sheltering effect and terrain type are not included in the implementation in ESP-r.

\subsubsection{Implementation in IES}

As in ESP-r, the model by McAdams is the default (and in IES the only) model for $h_{c, \text { ext }}$ calculation in IES. Its documentation reports the use of Eq. (2) with the roughness parameters for "smooth" surfaces (Table 2). As in the original model, it is applied irrespective of the type of building (high, medium or low-rise) and surface orientation regarding the wind direction (windward, leeward, roof). Variations in sheltering effects by other buildings and terrain type are also not taken into account. According to the IES documentation, "wind speed $(\mathrm{m} / \mathrm{s})$ read from the simulation weather file" is used in the implementation, i.e. $V_{10}$. It indicates that IES does not use any adjustment to convert $V_{f}$ into $V_{10}$. This implementation, including all assumptions, leads to $h_{c, \text { ext }}$ values about 3 to 4 times higher than those calculated by ESP-r for wind orthogonal to the surface and wind speed between 2 and $15 \mathrm{~m} / \mathrm{s}$. Users of IES can also override the calculated convection coefficient by providing a fixed $h_{c, e x t}$ value [37]. 


\subsubsection{Implementation in IDA}

Similar to IES and ESP-r, the model by McAdams is the default (and in IDA the only) model for $h_{c, \text { ext }}$ in IDA. In contrast to IES, this program uses Eq. (2) with the roughness parameters for "rough" surfaces (Table 2).

According to the IDA documentation, $V_{l o c}$ is used in Eq. (2) for the calculation of $h_{c, e x t}$, where $V_{l o c}$ is calculated using the model proposed by the ASHRAE task group [47]. The ASHRAE task group model is described in Section 2.9 of this paper (Eq.(25) and Eq. (26)); hence it is not reproduced in the present section. For windward surfaces, Eq. (25) is very similar to Eq. (6) used by ESP-r for wind attack angle $(\theta)$ below $10^{\circ}$. However, Eq. (25) is used by IDA for all wind attack angles. For leeward surfaces, the Eq. (26) used by IDA gives higher $h_{c, e x t}$ for low wind speeds and lower $h_{c, \text { ext }}$ values for high wind speeds when compared to ESP-r implementation. As in the original model, other factors such as building type (high, medium or low-rise), sheltering effect and terrain type are not included in the implementation in IDA.

\subsection{CIBS model [48]}

Similar to the model by McAdams, the expression proposed in the CIBS Guide [48] is based on Jürges' wind tunnel measurements [43]. The expression is as follows:

$$
h_{c, \text { ext }}=4.1 V_{\text {loc }}+5.8
$$

Eq. (9) is very similar to Eq. (4), indicating that it might be based on the linearized form of Eq. (2) using the average of the coefficients for rough and smooth surfaces. As mentioned before, Jürges' experiments are based on $V_{f}$, however the CIBS guide recommends the use of $V_{\text {loc }}$ according to Eq. (10) and (11)

For roofs, the expression is:

$$
V_{l o c}=V_{R}= \begin{cases}1 \mathrm{~m} / \mathrm{s} & \text { for sheltered buildings } \\ 3 \mathrm{~m} / \mathrm{s} & \text { for normal buildings } \\ 9 \mathrm{~m} / \mathrm{s} & \text { for severe buildings }\end{cases}
$$

"Sheltered" exposure refers to buildings with height up to 3 storeys in city centres. "Normal" exposure refers to buildings with height between 4 to 8 storeys in city centres, as well as most buildings in suburban areas and in the country side. "Severe" exposure refers buildings with more than 9 storeys in city centres, buildings with more than 5 storeys in suburban and country districts as well as all buildings on coastal areas or exposed on hills [48]. For other surfaces, the expression is:

$$
V_{l o c}=2 / 3 V_{R}
$$

Note that the exact distance at which $V_{R}$ should be taken is not mentioned [48]. This model only indirectly takes into account variations in building type (high, medium or low-rise) and it does not take into account variations in surface texture, surface orientation (windward, leeward and roof), and terrain types. Radiative heat exchange is also not included in this model.

\subsubsection{Implementation in ESP-r}

In ESP-r, Eq. (10) and (11) are not adopted to calculate $V_{\text {loc }}$. Instead, Eq. (12) is used.

$$
V_{l o c}=2 / 3 V_{10}
$$

This equation is applied to all building surfaces irrespective of surface texture and orientation, building type, sheltering effect and terrain type.

\subsubsection{Implementation in TAS}

The CIBS model is the default and the only model for $h_{c, \text { ext }}$ calculation implemented in TAS. As in the ESP-r implementation, Eq. (10) and (11) are not used to calculate $V_{l o c}$. Instead, TAS assumes $V_{l o c}=V_{l 0}$ in Eq. (9), providing results $30 \%$ to $45 \%$ higher than the implementation in ESP-r for wind speed between 3 and $15 \mathrm{~m} / \mathrm{s}$. This implementation does not consider variations in surface texture and orientation, building type (high, medium or low-rise), sheltering effect and terrain type. 


\subsection{BLAST detailed convection model $[49,50]$}

The Building Loads Analysis and System Thermodynamics (BLAST) model is based on wind tunnel experiments performed by Sparrow et al. [51] combined with conclusions from previous studies [52] and a number of assumptions and models described in secondary sources ${ }^{1}[49,50,53,54]$. Due to this combination, the model is more comprehensive than most other models. For example, it makes an explicit distinction between forced convection and natural convection. The total $h_{c, \text { ext }}$ is the sum of the natural $\left(h_{c, \text { nat }}\right)$ and forced $\left(h_{c, f o r}\right)$ components of convection:

$$
h_{c, \text { ext }}=h_{c, \text { for }}+h_{c, \text { nat }}
$$

The forced convection component is calculated using Eq. (14), which is based on results of wind tunnel experiments using rectangular plates [51]:

$$
h_{c, f o r}=2.537 W_{f} R_{f}\left(\frac{P V_{f}}{A}\right)^{1 / 2}
$$

where $h_{c, f o r}$ is given in $\mathrm{W} / \mathrm{m}^{2} \mathrm{~K}, W_{f}$ is the wind direction modifier, $R_{f}$ is the surface roughness multiplier, $P$ is the perimeter of the surface (m) and $A$ is the area of the surface $\left(\mathrm{m}^{2}\right)$. In Eq. (14), $W_{f}$ is equal 1 and 0.5 for windward and leeward surfaces, respectively [52], where leeward is defined as the surface with wind attack angle greater than 100 degrees from the normal incidence [49]. Values of $R_{f}$ are based on the surface conductance graph in ASHRAE 1981 [53] and can be taken from Table 3. These values range from 1 for very smooth surfaces to 2.17 for very rough surfaces, indicating that, according to this model, $h_{c, \text { ext }}$ is up to $117 \%$ higher for rough surfaces than for smooth ones. The parameters $\mathrm{A}$ and $\mathrm{P}$ also affect significantly $h_{c, f o r}$. For example, doubling $\mathrm{A}$ of a squared surface reduces $h_{c, f o r}$ by $30 \%$. The reason for the relation between $h_{c, f o r}$ and A is likely twofold: (1) the growth of the boundary layer, with consequent reduction in the transfer coefficient, and (2) the reduced importance of higher losses near edges of the surface due to possible flow separation.

The experimental work of Sparrow et al. [51] was performed for rectangular plates placed in the wind tunnel and the results are based on $V_{f}$. However, the BLAST detailed convection model assumes $V_{f}$ equal to $V_{z}$, which is calculated according to the following expression:

$$
V_{f}=V_{z}=V_{9.14}\left(z / z_{f}\right)^{1 / \gamma}
$$

where $V_{9.14}$ is the wind speed measured at a weather station at $9.14 \mathrm{~m}(=30 \mathrm{ft})$ above ground $(\mathrm{m} / \mathrm{s}), z_{f}$ is the height at which standard wind speed measurements are taken (i.e. $9.14 \mathrm{~m}$ ), $z$ is the height above ground of the centre of the wall (m) and $\gamma$ is the terrain dependent coefficient [49].

The natural convection component is calculated using Eq. (16) and (17). These equations are published in a secondary source, in which the original source is not mentioned [54].

Ascending flows $\left(T_{s}>T_{a}\right)$ :

$$
h_{c, \text { nat }}=9.482 \frac{\left(\left|T_{s}-T_{a}\right|\right)^{1 / 3}}{7.238-|\cos \phi|}
$$

Descending flows $\left(T_{s}<T_{a}\right)$ :

$$
h_{c, \text { nat }}=1.810 \frac{\left(\left|T_{s}-T_{a}\right|\right)^{1 / 3}}{1.382+|\cos \phi|}
$$

where $h_{c, \text { nat }}$ is given in $\mathrm{W} / \mathrm{m}^{2} \mathrm{~K}, \mathrm{~T}_{\mathrm{s}}$ is the surface temperature, $\mathrm{T}_{\mathrm{a}}$ is the air temperature and $\phi$ is the surface plane slope angle in relation to the ground plane $\left(^{\circ}\right)$. Note that Eq. (16) and (17) are equivalent when the wall is vertical $\left(\phi=90^{\circ}\right)$.

Although this model is rather comprehensive, it does not take into account variations in building type (high, medium or low-rise), surface orientation, sheltering effects by other buildings and it is also not clear how $h_{c, \text { ext }}$ should be calculated for roof surfaces. Radiative heat exchange is not included in this model.

\subsubsection{Implementation in EnergyPlus}

The implementation in EnergyPlus is very similar to the original model. The only difference is the use of Eq. (18) to calculate $V_{f}$ instead of Eq. (15) [36]:

\footnotetext{
${ }^{1}$ Secondary sources are publications which reproduce the content originally presented in another publication.
} 


$$
V_{f}=V_{z}=V_{10}\left(\frac{\delta_{f}}{z_{f}}\right)^{c_{f}}\left(\frac{z}{\delta}\right)^{c}
$$

where $\delta_{f}$ is the atmospheric boundary layer thickness at the weather station (m) (given in Table 4, terrain type 3), $z_{f}$ is the height at which standard wind speed measurements are taken $(\mathrm{m})$ (usually $10 \mathrm{~m}$ above the ground level), $c_{f}$ is the wind speed profile exponent at the weather station (given in Table 4, terrain type 3 ), $z$ is the height above ground level (in this case the height of the centre of the surface) (m), $\delta$ is the atmospheric boundary layer thickness at the building site (m), and $c$ is the wind speed profile exponent at the building site (given in Table 4) [55]. EnergyPlus also applies this model for roof surfaces, but the documentation does not mention the value for $W_{f}$ that should be used for roofs. As in the original model, the implementation does not take into account the building type (high, medium or low-rise) and sheltering effect.

\subsection{TARP detailed convection model [54]}

The Thermal Analysis Research Program (TARP) model is very similar to the BLAST model. The only difference is the use of Eq. (19) to calculate $V_{f}$ instead of Eq. (15):

$$
V_{f}=V_{z}=V_{10} \beta\left(z / z_{f}\right)^{\alpha}
$$

where $\alpha$ and $\beta$ are the terrain roughness coefficients that are given in Table 5 .

\subsubsection{Implementation in EnergyPlus}

The TARP model was originally implemented in EnergyPlus, but starting from versions 1.3.0 of EnergyPlus, the TARP model implementation is identical to the BLAST model implementation and Eq. (19) is no longer used.

\subsection{ASHRAE detailed model [36]}

This model is also very similar to the BLAST model. The only difference is the use of Eq. (18) to calculate $V_{f}$ instead of Eq. (15) [36]. It means that the ASHRAE detailed model is identical to the BLAST model and the TARP model implementations in EnergyPlus. Probably, the three models are available in EnergyPlus for historical reasons, assuring compatibility with EnergyPlus files created using previous versions. However, all the models will produce the same results.

\subsection{NBS polynomial model [56]}

This model was published in the National Bureau of Standards (NBS) building science series and it uses a polynomial expression based on surface conductance curves available in the ASHRAE Handbook of Fundamentals 1981 [53]. These surface conductance curves were derived from experiments using 12-in. square samples of different materials [57, 58]. The following expression is derived based on these conductance curves:

$$
h_{\text {ext }}=D+E V_{10}+F V_{10}^{2}
$$

where $h_{e x t}$ is the combined radiative and convective coefficient and $D, E$ and $F$ are the roughness coefficients (Table 6). Concerning the wind speed, the model adopts $V_{10}$, although the conductance curves were obtained in wind tunnel experiments based on $V_{f}$. [57, 58]. As emphasised by Cole and Sturrock [52], these conductance curves are not applicable to all the surfaces on the building exterior because they were derived for horizontal surfaces with parallel wind flow.

As mentioned before this model yields a combined convective and radiative heat transfer coefficient, i.e. radiation to the sky, ground and air is also included [56], which implies large simplifications in the representation of the heat transfer process as it ignores, among other factors, variations in the sky temperature due to cloud cover. This model does not take into account variations in building type (high, medium or low-rise), surface orientation (windward, leeward, roof), sheltering effect by other buildings and terrain types.

\subsubsection{Implementation in EnergyPlus}

The implementation in EnergyPlus is slightly different from Eq. (20). Instead of $V_{l o}$, EnergyPlus uses $V_{z}$ calculated according to Eq. (18). This model is applied to all surfaces, irrespective of the surface orientation, the building type and sheltering conditions. However, EnergyPlus does consider the effect of the terrain type by applying Eq. (18). 


\subsection{Model by Jayamaha et al. [59]}

This model is derived from field measurements carried out using a free-standing aluminium plate mounted at the centre of a large plywood sheet $(1.8 \mathrm{~m} \times 1.2 \mathrm{~m})$ and shaded from direct solar radiation by using an opaque shield. The following expression is proposed [59]:

$$
h_{c, \text { ext }}=1.444 \mathrm{~V}+4.955
$$

Jayamaha et al. do not specify the definition of the wind speed $\mathrm{V}\left(V_{10}, V_{f}, V_{R}\right.$ or $\left.V_{l o c}\right)$ to be used in Eq. (21). Radiative heat exchange is not included in this model. This model does not take into account variations in building type (high, medium or low-rise), surface texture, surface orientation (windward, leeward, roof), sheltering effect by other buildings and terrain types.

\subsubsection{Implementation in ESP-r}

The ESP-r implementation of this model uses $V_{10}$ in Eq. (21) and applies it to all building types (high, medium or low-rise), surface textures and orientations (windward, leeward, roof), sheltering conditions and terrain types.

\subsection{Model by Sturrock [60, 61]}

This model is based on field measurements using nichrome strips on a 26-m high building and uses $V_{R}$ measured using a mast-mounted anemometer [60]. It provides two relationships, as follows [61]:

Exposed surfaces:

$$
h_{c, \text { ext }}=6.1 V_{R}+11.4
$$

Normal surfaces:

$$
h_{c, e x t}=6 V_{R}+5.7
$$

with $\mathrm{V}_{\mathrm{R}}$ in $\mathrm{m} / \mathrm{s}$. Sheltering conditions are considered in this model. The model does not take into account variations in the building type (high, medium or low-rise), surface texture, surface orientation (windward, leeward, roof) and terrain types. Radiative heat exchange is not included in this model.

\subsubsection{Implementation in ESP-r}

In the ESP-r implementation, the wind speed at roof $V_{R}$ is substituted by $V_{10}$, and only the expression for exposed surfaces is implemented (Eq. (22)). This equation is applied for all types of buildings, all building surfaces (smooth/rough, windward/leeward/roof, exposed/sheltered) and all terrain types.

\subsection{ASHRAE task group model [47, 62]}

This model is based on the results from Ito et al. [62], who performed experiments on the facade of a 6-storey building with an open L-shaped plan in Tokyo. From these results, the ASHRAE task group has derived the following expressions:

$$
h_{c, e x t}=18.6 V_{l o c}^{0.605}
$$

where $V_{l o c}$ is given by Eq. (25) and (26).

Windward:

$$
V_{l o c}= \begin{cases}0.5 \mathrm{~m} / \mathrm{s} & \text { for } V_{10}<2 \mathrm{~m} / \mathrm{s} \\ 0.25 V_{10} & \text { else }\end{cases}
$$

Leeward:

$$
V_{l o c}=0.05 V_{10}+0.3 \mathrm{~m} / \mathrm{s}
$$

In the original experimental work by Ito et al. [62], $V_{R}$ and $V_{\text {loc }}$ were measured at $8 \mathrm{~m}$ above the roof and 0.3 $\mathrm{m}$ from the surface, respectively. However, it can be noticed that $V_{R}$ has been replaced with $V_{10}$ in the model by the ASHRAE task group (Eq. (25) and (26). Regarding the surface texture, copper plates have been used for the measurements; hence it can be assumed that this model is applicable to smooth surfaces. Further information regarding the sheltering effect by other buildings and terrain type correction could not be found in the available references $[47,62]$. Note that this model was derived for a very specific building shape (open L-shaped plan) and might therefore not provide realistic values for other building geometries. Radiative heat transfer is not included in this model. 


\subsubsection{Implementation in ESP-r}

The implementation in ESP-r is identical to Eq. (24), (25) and (26). While the model was derived for vertical and smooth surfaces, ESP-r applies this model to all types of buildings with different surface textures and orientation (windward, leeward and roof). Sheltering effect and the terrain type were not considered in the original model, and are also not considered in its implementation in ESP-r.

\subsection{Model by Nicol [63]}

This model is based on nocturnal field measurements for an external window in arctic regions in Canada [63] and is given by:

$$
h_{c, \text { ext }}=7.55 V_{R}+4.35 \quad \text { for } 0<V_{R}<5.0 \mathrm{~m} / \mathrm{s}
$$

Wind speed measurements were performed at the roof top of a building, but the exact measurement height is not mentioned. As can be seen from the above expression, a wind speed restriction of maximum $5 \mathrm{~m} / \mathrm{s}$ is reported for this model. The reason of this restriction is not reported in Ref. [63], and it is probably related to the wind speed range measured during the experiment. The model is applicable to vertical smooth surfaces with windward orientation. Note however that the definition of windward by this model is not described in Ref. [63]. According to the sketch of the surroundings provided in Ref. [63], the building used for the experiment is located in a moderately densely-built area. The model does not take into account variations in the building type (high, medium or low-rise), surface texture, surface orientation (windward, leeward, roof), sheltering effect by other buildings and terrain types. Radiative heat exchange is not included in this model.

\subsubsection{Implementation in ESP-r}

In ESP-r, $V_{R}$ is replaced by $V_{10}$ in Eq. (27). This equation is applied to all types of buildings, building surfaces (smooth/rough, windward/leeward/roof, exposed/sheltered) and terrain types.

\section{$2.11 \quad$ Model by Loveday \& Taki [64]}

The model is based on full-scale measurements for an 8-storey building with a total height of $28 \mathrm{~m}$, situated in a semi-urban environment at the Loughborough University of Technology, UK [64]. The test panel was installed on the facade of the $6^{\text {th }}$ floor $(21 \mathrm{~m}) . V_{R}$ (up to $16 \mathrm{~m} / \mathrm{s}$ ) and $V_{l o c}$ (up to $9.5 \mathrm{~m} / \mathrm{s}$ ) were measured at $11 \mathrm{~m}$ above the roof and at $1 \mathrm{~m}$ from the test panel, respectively. From these measurements, the equations for windward and leeward facades presented in Table 7 and Table 8 were obtained. The expressions are suitable for vertical smooth surfaces with windward or leeward orientations. The model is recommended for multi-storey buildings with between four and eight storeys [64]. Like most of the models described in the present paper, the model by Loveday \& Taki model does not provide an equation for the roof. Variations in the sheltering effects by other buildings are also not considered in this model and radiative heat exchange is not included.

\subsubsection{Implementation in ESP-r}

ESP-r implementation replaced $V_{R}$ by $V_{10}$ in the equations in Table 8 . The original model provides two equations in Table 8 for windward surfaces, the first for wind attack angles $(\theta)$ between $0^{\circ}$ and $70^{\circ}$, and a second for wind attack angles between $70^{\circ}$ and $90^{\circ}$. However, in ESP-r only the first equation is implemented for windward surfaces. Similar to the implementation of other models, ESP-r applies this model for all building types, all types of surfaces, irrespective of their orientation and texture, for different sheltering conditions and terrain types. In ESP-r, the roof is assumed to have the same $h_{c, \text { ext }}$ as a surface facing north, i.e. sometimes the roof is treated as a windward or as a leeward surface, depending on the wind direction. This assumption is not likely to provide accurate results, however this model is not supposed to predict $h_{c, \text { ext }}$ values of roofs. Therefore, it is clear that this assumption is only used in the ESP-r code to avoid execution errors in cases where the user wrongly selects this $h_{c, \text { ext }}$ model for a roof surface.

\subsection{Model by Hagishima \& Tanimoto [65]}

This model is based on field measurements performed on a building composed of a 2-storey building (9.9 m) attached to and sheltered by a 4-storey building $(16.5 \mathrm{~m})$ [65]. The model has several expressions for $h_{c, \text { ext }}$, however only the two expressions used in ESP-r are reproduced below.

For horizontal surfaces: 


$$
h_{c, e x t}=2.28 V_{R}+8.18
$$

For vertical surfaces:

$$
h_{c, \text { ext }}=10.21 V_{\text {loc }}+4.47
$$

$V_{R}$ was measured on top of the 2-storey building, at $0.6 \mathrm{~m}$ above the roof while $V_{l o c}$ was measured at $0.13 \mathrm{~m}$ from a vertical surface of a cube (edges of $2.4 \mathrm{~m}$ ) placed on the roof of the 4-storey building (measurement height was not given in the original paper), $\mathrm{V}_{\mathrm{R}}$ ranged from 0.2 to $7.5 \mathrm{~m} / \mathrm{s}$, while $\mathrm{V}_{\text {loc }}$ ranged from 0.5 to $3.0 \mathrm{~m} / \mathrm{s}$. No exact information was provided about the building surroundings and consequently about the sheltering effect at the vertical surface, mounted on the 4-storey building. The roof of the 2 -storey building is clearly sheltered by the attached 4-storey building, therefore the equation for horizontal surfaces is likely to be only suitable for sheltered conditions. Experiments were performed for surfaces of the cube covered with wood or asphalt. The expression for vertical surfaces was derived for wind parallel or orthogonal to the building surface, therefore it might not be suitable for leeward surfaces. This model does not take into account variations in the terrain type and also radiative heat transfer is not considered.

The model by Hagishima \& Tanimoto is the only model implemented in BES that gives a specific expression for $h_{c, \text { ext }}$ based on measurements on a roof rather than only using the same expressions as for the facade, as done in the previously discussed models. It is clear that all models described in this paper have limited applicability due to the particular building geometry adopted. However the rather unusual building shape in the model of Hagishima \& Tanimoto, (a 2-storey building attached and sheltered by a 4-storey building) is particularly less applicable to rectangular block-type building shapes.

\subsubsection{Implementation in ESP-r}

As for other models implemented in ESP-r, the implementation of the model by Hagishima \& Tanimoto replaces $V_{R}$ by $V_{10}$ in Eq. (28) and assumes $V_{l o c}$ equal to $2 / 3$ of $V_{10}$ in Eq. (29). ESP-r applies this model to all surface textures and orientations, including leeward surfaces (not considered in the original model). As in the original model, there is no consideration for different building types, sheltering effects and terrain types in the implementation.

\subsection{MoWiTT model [66]}

This model is based on the experiments carried out at the Mobile Window Thermal Test (MoWiTT) facility by Yazdanian and Klems [66]. The proposed expression is:

$$
h_{c, \text { ext }}=\sqrt{\left(C_{t}\left(T_{s}-T_{a}\right)^{1 / 3}\right)^{2}+\left(a V_{10}^{b}\right)^{2}}
$$

where $C_{t}$ is the turbulent natural convection constant, $\mathrm{T}_{\mathrm{s}}$ is the surface temperature, $\mathrm{T}_{\mathrm{a}}$ is the air temperature and $a$ and $b$ are the constants for windward and leeward surfaces. These constants are given in Table 9. A good agreement between experiments and model seems to be indicated by low uncertainty for the constants $a$ and $b$.

Similar to the BLAST and TARP detailed convection models, Eq. (30) is composed of two terms to calculate both the natural and the forced convection coefficient. This model is applicable to vertical smooth surfaces (windows) with windward or leeward orientation and for low-rise buildings. Sheltering effects and terrain types are not considered in this model. This is the only model implemented in both ESP-r and EnergyPlus.

\subsubsection{Implementation in ESP-r}

The implementation in ESP-r is exactly the same as the original model. The use of $V_{10}$ by this model simplifies its implementation, because no assumptions and/or models are necessary to obtain $V_{R}$ and $\mathrm{V}_{\text {loc }}$. The program applies the model to all building surfaces irrespective of their building types (low, medium or high-rise), surface textures, sheltering conditions or terrain types. In the ESP-r implementation, the roof is assumed to have the same $h_{c, \text { ext }}$ as a surface facing north. This assumption regarding $h_{c, \text { ext }}$ of roofs is consistent with the one adopted in the implementation of the model by Loveday and Taki. Note however that the MoWiTT is not supposed to predict $h_{c, \text { ext }}$ values of roofs. Therefore, it is clear that this assumption is only used in ESP-r code to avoid execution errors in cases where the user wrongly selects this $h_{c, \text { ext }}$ model for a roof surface.

\subsubsection{Implementation in EnergyPlus}

According to the EnergyPlus documentation, the program recommends the use of this model for vertical smooth surfaces with windward or leeward orientations and for low-rise buildings. Instead of using $V_{10}$, the local wind 
speed modified for a specific height $\left(V_{z}\right)$, calculated from Eq. (18) is implemented in this code. The exact height at which the wind speed should be calculated however is not clear. By taking this approach, EnergyPlus considers different terrain types in the implementation of this model. The program however does not take into account variations in the sheltering effects by surrounding buildings. EnergyPlus also applies this model for roof surfaces, but the documentation does not mention the values of the parameters $\mathrm{a}$ and $\mathrm{b}$ for these surfaces.

\subsection{DOE-2 model [67]}

The DOE-2 model is a combination of the BLAST and the MoWiTT models and proposes the following expression for "very" smooth surfaces:

$$
h_{c, \text { ext }}=\sqrt{h_{c, n a t}{ }^{2}+\left(a V_{10}{ }^{b}\right)^{2}}
$$

The constants $a$ and $b$ can be extracted from Table 9. The first term, which accounts for buoyancy-driven flows, is calculated using Eqs. (16) and (17). For non-smooth surfaces, the value for $h_{c, \text { ext }}$ is calculated by:

$$
h_{c, \text { ext }}=\left(1-R_{f}\right) \cdot h_{c, n a t}+R_{f} \cdot \sqrt{h_{c, n a t}{ }^{2}+\left(a V_{10}{ }^{b}\right)^{2}}
$$

where $R_{f}$ can be taken from Table 3 (also used in the BLAST detailed convection model).

This model considers different surface textures (Table 3), windward and leeward orientations and different surface slope angles. The model is suitable for low-rise buildings. This model does not take into account variations in the sheltering effect by other buildings and variations in the terrain types.

\subsubsection{Implementation in EnergyPlus}

The DOE-2 model is the default model in EnergyPlus. The implementation is very similar to the original model, however the local wind speed modified for specific height $\left(V_{z}\right)$ calculated using Eq. (18) is used in the implementation instead of $V_{10}$. Similar to the implementation of MoWiTT model, the exact height at which the wind speed should be calculated is not clear. Eq. (18) is integrated in the model, hence EnergyPlus considers different terrain types in the calculation. The program does not take into account variation in the sheltering effect by other buildings. As in the implementation of the MoWiTT model, EnergyPlus also applies this model for roof surfaces, but the documentation does not mention the values of the parameters $\mathrm{a}$ and $\mathrm{b}$ for roofs.

\subsection{Model by Liu \& Harris [68]}

This model is based on full-scale experiments performed on the facade of a single-storey building in a rural environment partially sheltered by tree belts and a nearby building [68]. The equations for $h_{c, \text { ext }}$ are reproduced in Table 10. The model provides equations based on $V_{l o c}$ (up to $3 \mathrm{~m} / \mathrm{s}$ ), $V_{R}$ (up to $9 \mathrm{~m} / \mathrm{s}$ ), and $V_{l 0}$ (up to $16 \mathrm{~m} / \mathrm{s}$ ) which were measured $0.5 \mathrm{~m}$ away from the wall surface, $1 \mathrm{~m}$ above the roof and $10 \mathrm{~m}$ above the ground level, respectively. In Table 11, the relationships between the different wind speeds are expressed. Note that equations based on different wind speeds lead to different prediction of $h_{c, \text { ext }}$. The reason for this is not clear. Considering the availability of $V_{10}$ in BES weather files, it is advisable to use the equations based on $V_{10}$.

Radiative heat transfer is not included in this model. Regarding the surface texture, a copper sheet was used in the experiments; therefore this model is expected to be intended for smooth surfaces. The model distinguishes between windward and leeward surfaces. It is applicable for low-rise buildings in sheltered conditions. The terrain type where the experiments were carried out is not mentioned [68].

\subsubsection{Implementation in ESP-r}

All expressions in Table 10 and Table 11 are implemented in ESP-r. In this program, the user can choose between the different expressions (expressions based on $V_{l o c}, V_{R}$, and $V_{10}$ ). ESP-r uses this model for all building types, surface textures, sheltering conditions and terrain types. In the ESP-r implementation, the roof is assumed to have the same $h_{c, \text { ext }}$ as a surface facing north. This assumption regarding $h_{c, \text { ext }}$ of roofs is consistent with the one adopted in the implementation of the model by Loveday and Taki, and by the MoWiTT model, and it is clearly adopted here for the same reasons. 


\subsection{Loveday mixed model [35]}

This model is implemented in the ESP-r source code, however there is no reference to the original publication of this model. Therefore, differently from the previous sections, this section only describes the model implementation in ESP-r without separate sub-section(s). The following equation is implemented:

$$
h_{c, e x t}=16.7 V_{l o c}^{0.5}
$$

where ESP-r assumes $V_{l o c}$ to be equal to $2 / 3$ of $V_{10}$. ESP-r applies this model to all types of surfaces disregarding building type, surface texture, orientation (windward, leeward, roof), sheltering conditions and terrain types.

\section{$2.17 \quad$ British standard model [69]}

This model is reported in the British standard [69]. No information could be found about the experimental setup that was used to derive it. The model is:

$$
h_{c, e x t}=4 V+4
$$

where $\mathrm{V}$ is the "velocity over the surface". Note that $\mathrm{V}$ might refer to $V_{f}$ or to $V_{\text {loc }}$. Radiation is not included in the model. This model does not take into account variations in building type (high, medium or low-rise), surface texture, surface orientation (windward, leeward, roof), sheltering conditions and terrain type.

\subsubsection{Implementation in ESP-r}

ESP-r uses $V_{10}$ in Eq. (34). Similar to the implementation of previously discussed models in ESP-r, the program applies it to all building types, surface textures and orientations (windward, leeward, roof), sheltering conditions and terrain types.

\subsection{Simplified approaches}

Some approaches adopted by BES programs are grouped in Table 1 under the classification "Simplified approaches". This section briefly describes these approaches and the relevant aspects of their implementation.

The simplest approach is the use of fixed values of $h_{c, \text { ext }}$ defined by the BES program for the whole simulation duration and for all surfaces, which is possible in 4 out of 7 programs. Users can impose different $h_{c, e x t}$ values (fixed or variable in time) for each surface in 3 out of 7 programs. However, it is highly unusual that BES users will have ready-to-use and accurate $h_{c, \text { ext }}$ values as input for their simulations. The option of userdefined values, profiles or correlations is available in BES programs for validation purposes (in exercises where $h_{c, e x t}$ must be imposed [44]), sensitivity analyses [70] and more recently for the external coupling with CFD simulations which provide detailed transfer coefficients for BES simulations, usually however only for the indoor environment $[71,72]$. The option of adopting user-define values, profiles or correlations is rarely applicable for real buildings as experiments or CFD simulations for a particular building shape are quite expensive and time-consuming.

It is known that heat transfer at exterior building surfaces is influenced by moisture fluxes, particularly winddriven rain [11, 12, 73-75], due to latent and sensible heat related to vapour diffusion and rain

absorption/evaporation by porous building materials. Moreover, even for impervious surfaces, wind-driven rain will play a role in the heat transfer at these building surfaces, due to the temperature difference between the rain and the surface, as well as the evaporation of the thin water film and/or droplets attached to the surface by surface tension [76, 77]. However BES programs usually do not take into account moisture related phenomena in the calculation of heat transfer at exterior building surfaces. The exception is EnergyPlus, which adopts a simplified approach to take into account, at least partially, the impact of rain events on the building facade heat transfer. In EnergyPlus, "when the outside environment indicates that it is raining, the exterior surfaces (exposed to wind) are assumed to be wet. The convection coefficient is set to a very high number (1000) and the outside temperature used for the surface will be the wet bulb temperature." [36]. This approach involves major simplifications of the physical processes related to moisture transfer taking place in external building surfaces, and no validation of this approach is reported in the EnergyPlus documentation. A more detailed calculation would need to take into account the amount of rain reaching each surface, the moisture transport properties of the material and mainly the latent heat involved in the moisture transfer at the surface $[12,13,74]$. 


\section{Comparison of $\boldsymbol{h}_{c, e x t}$ models}

\subsection{Comparison of $h_{c, e x t}$ model completeness}

Based on Section 2, it can be concluded that there is no $h_{c, \text { ext }}$ model implemented in any of the 7 selected BES programs that takes into account all the factors which influence $h_{c, e x t}$, as listed in Section 1 . On the other hand, there is always a minimum combination of factors included in each model. Assuming fixed properties for the air flowing around the buildings, 9 relevant factors for $h_{c, \text { ext }}$ models can be identified:

- Wind speed

- Wind direction in relation to the surface orientation (wind attack angle)

- Surface orientation relative to wind in qualitative terms (windward, leeward)

- $\quad$ Surface slope angle in relation to the ground plane (horizontal and vertical as extreme case)

- Terrain type

- $\quad$ Sheltering by nearby buildings

- Surface texture

- $\quad$ Surface to air temperature difference $(\Delta T)$

- $\quad$ Surface size and aspect ratio

Building type (high, medium or low-rise) and building geometry are also a relevant factor in the calculation of $h_{c, e x t}$. However these factors are not included in the list because none of the models described in overview are capable of taking variations in building type and geometry into account.

Table 12 compares the convection models based on the above-mentioned factors, allowing an evaluation of the completeness of each model. One the one hand, it can be noticed from the table that wind speed is the only factor considered in all models. On the other hand, the sheltering effect by adjacent buildings on $h_{c, \text { ext }}$ is taken into account by only two convection models (the models by CIBS and by Sturrock) in spite of its recognized importance for flow around buildings [18, 19, 21, 27, 34, 78]. Regarding completeness of models, the BLAST model and related ones are the most complete, because they take in to account 7 out of 9 factors. However, the implementations of the BLAST model and related models are based on the assumption that $V_{f}$ is equal to $V_{z}$, while the use of $V_{10}$ in the model would be preferable considering that it is the type of reference wind data available in BES programs. Of the remaining models, the MoWitt and DOE-2 models are most complete, and they also both have the advantage of being based on full-scale experiments using $V_{10}$.

\subsubsection{Reference wind speed, building geometry and spatial scale used in the experiments}

The models in Table 12 are divided in 4 groups: reduced-scale experiments, full-scale experiments without $V_{10}$, full-scale experiments with $V_{10}$ and a group with "other models". The last group is composed by rather simple models with very little information available, which might compromise their suitability for BES applications. Hence these models are not addressed in detail in the present section. The group of models based on reducedscale experiments, shows a large variation in their completeness, but from Section 2 it is possible to see that all these models were derived from experiments using flat plates. Due to the fact that the building geometry is completely ignored, the applicability of these models for buildings is very questionable. Moreover, the implementation of these models based on reduced-scale experiments using $V_{f}$ or $V_{l o c}$ requires assumptions in the reference wind speed (because BES only provides $V_{10}$ ), increasing their uncertainty. Therefore, models based on reduced-scale experiments based on $V_{f} / V_{\text {loc }}$ or using flat plates should be used with extreme caution, and for this reason they are not addressed in the following sections of this paper.

\subsubsection{Experimental setup used in the development of $h_{c, \text { ext }}$ model}

The variation in completeness between models shown in Table 12 can be partially attributed to the different experimental setups from which they were derived. Table 13 presents a brief review of the experimental setup of some $h_{c, \text { ext }}$ models based on full-scale experiments. The model by McAdams is additionally included in Table 13 due to its frequent use in BES programs. The DOE-2 model is not included because it is very similar to the MoWiTT model. Moreover, the use of roughness multipliers from Table 3 by DOE-2 model involve assumptions with unknown impact on the $h_{c, \text { ext }}$ calculations, rendering the use of this model less advisable. Table 13 is based on information available in scientific publications, and missing information about the experiments is indicated by “-”.

The amount of missing information of some models in Table 13 is very large, such as the models by Nicol and by Sturrock, while other models provide much more details about the measurement setup, such as the models by Loveday \& Taki and by Liu \& Harris. From this table, it is possible to see that the experimental setup varies 
drastically between the models, with large differences in the wind speed measurement range at the site, the position of sensors for $V_{l o c}$ and $V_{R}$, the building geometry, etc. While using a specific convection model, Table 13 can help users to choose the model applicable for a particular case. Generally speaking, each model is suitable for the micro-climatic condition it was developed. Using a model in different micro-climatic conditions can lead to erroneous results. Careful attention should be paid towards the wind speed range, definition of reference wind speed adopted, building geometry and the ways sheltering effects were addressed in the model.

\subsection{Comparison of $h_{c, \text { ext }}$ values predicted by 6 models}

6 models from Table 13 were selected for a detailed comparison, in order to demonstrate differences in the calculated $h_{c, \text { ext }}$. The models by Sturrock and by Nicol were not included due to the lack of information about their experimental setup. The results of the comparison are shown in Figure 2 for vertical surfaces with windward and leeward orientations under different wind speeds and wind attack angles. Values plotted in the graph are in some cases outside the limits of applicability of the correlations. However, note that Figure 2 reproduces the values obtained in BES simulations, where no measures have been implemented to prevent the use of correlations outside their limits of applicability.

\subsubsection{Comparison for windward and leeward surfaces}

Figure 2a shows the predictions of $h_{c, \text { ext }}$ for a vertical windward surface with wind attack angle $\theta=0^{\circ}$. Results shows that all models present a similar trend except the model by Hagishima \& Tanimoto, which predicts much higher values for $h_{c, \text { ext }}$ for $\mathrm{V}_{10}$ above about $3 \mathrm{~m} / \mathrm{s}$. Similar differences can be observed in Figure $2 \mathrm{~b}$ and Figure $2 \mathrm{c}$. This behaviour can be attributed to the implementation assumption of the Hagishima and Tanimoto model in ESP-r regarding the relation between $V_{l o c}$ and $V_{l 0}$. The model by Hagishima and Tanimoto model adopts $V_{l o c}$, while BES programs, including ESP-r, adopt $V_{10}$ in their weather files. The implementation of this model in ESP-r assumes that $V_{l o c}$ is equal to $2 / 3$ of $V_{10}$ irrespective of the wind direction. Based on experiments, other models adopt values much lower than $2 / 3$ for this relation, around 0.26 for windward orientation (such as in Table 11) and 0.19 for leeward orientation (such as in Table 11). The differences between the model by Hagishima and Tanimoto and other models highlights the problem of using models not based on $V_{l 0}$ in BES programs. This requires assumptions to obtain $V_{l o c}$, or other types of reference wind speed. The use of these models should therefore be avoided. It is however also important to stress that the model by Hagishima and Tanimoto was developed using a very particular building shape, which further limits the general applicability of this model.

Figure $2 \mathrm{a}$ and $\mathrm{b}$ also show that the lowest values of $h_{c, \text { ext }}$ are obtained by the model by McAdams (as implemented in ESP-r) which was derived for a flat plate. The same observation is obtained from for some wind attack angles in Figure 2(C).

\subsubsection{Comparison for low-rise and high-rise buildings}

Disregarding the models by McAdams and by Hagishima and Tanimoto, two groups can be identified in Figure 2. The first one consists of the models by the ASHRAE task group and by Loveday \& Taki and the second one consists of the models by Liu \& Harris and by MoWiTT. In both groups the models show a remarkable agreement. It is most pronounced in Fig. 2a, but also clear in Fig. 2c and to a lesser extent also in Fig. 2b, particularly for $\mathrm{V}_{10}$ between approximately 3 and $7 \mathrm{~m} / \mathrm{s}$. This agreement can be in part attributed to the building geometry used in the experiments related to these models. Table 13 shows that the models by the ASHRAE task group and by Loveday \& Taki were both derived from experiments on buildings with 6 to 8 storeys, while the models by Liu \& Harris and by MoWiTT were derived from experiments on a 1-storey building. This agreement is particularly relevant considering that several other aspects of the models and their experimental setups differ significantly, as well as some assumptions on their implementation in BES. The fact that this agreement is obtained under such conditions suggest that the predictions provided by these 2 groups of models are representative of buildings in general with 6 to 8 storeys (ASHRAE task group and Loveday \& Taki models) and with 1 storey (models by Liu \& Harris and by MoWiTT). Comparing these two groups of models, it is noticeable that $h_{c, \text { ext }}$ is higher for high building (6 to 8 storeys) than for low buildings ( 1 storey), which seems logical given the larger exposure of higher buildings to wind flow in the atmospheric boundary layer.

This section provided a comparison of different models for $h_{c, e x t}$, and of the values of their predictions. The following section discusses the impact of using different convection model on typical BES results for a simplified model of an isolated, well-insulated three-storey building. 


\section{Uncertainty in BES results due to the use of different convection models}

To investigate the importance of choosing an appropriate convection model for BES simulations, calculations have been performed for an isolated (unsheltered) cubic building $\left(10 \times 10 \times 10 \mathrm{~m}^{3}\right)$. The 3-storey building with one zone per floor is inspired by the BESTEST case 600 [44], but with larger dimensions and a higher level of insulation for the walls $\left(0.4 \mathrm{~W} / \mathrm{m}^{2} \mathrm{~K}\right)$. The wall is composed of (from outside to inside) finishing wood (thickness $0.009 \mathrm{~m}$; thermal conductivity $0.14 \mathrm{~W} / \mathrm{m} . \mathrm{K})$, fiberglass quilt insulation $(0.066 \mathrm{~m} ; 0.04 \mathrm{~W} / \mathrm{m} . \mathrm{K})$ and a plaster layer $(0.012 \mathrm{~m} ; 0.16 \mathrm{~W} / \mathrm{m} . \mathrm{K})$. Note that the insulation level can an important role in the sensitivity of BES results to $h_{c, \text { ext }}$, especially for the calculation of cooling loads, when convective heat transfer from the exterior surface that is exposed to the solar radiation is important. For the calculation of heating loads, the sensitivity to $h_{c, e x t}$ is generally much lower, because the thermal resistance due to convection is small when compared to the overall wall resistance. By adopting a sufficiently high level of insulation, the results can be extrapolated with confidence to a large part of the building stock (mainly new or renovated buildings with HVAC). Roof and floor are modelled as in the BESTEST case $600\left(0.32 \mathrm{~W} / \mathrm{m}^{2} \mathrm{~K}\right.$ and $0.04 \mathrm{~W} / \mathrm{m}^{2} \mathrm{~K}$ respectively), shortwave external absorptivity of walls and roof is 0.6 and emissivity is 0.9 . Each story has 2 windows of $2 \mathrm{~m} \times 3 \mathrm{~m}$ facing south, with solar heat gain coefficient of 0.787 . Each story has internal constant heat gains of $200 \mathrm{~W}$ and a constant infiltration/ventilation rate of 0.5 air changes per hour. Cooling and heating set points of the fully convective cooling/heat systems are $27^{\circ} \mathrm{C}$ and $20^{\circ} \mathrm{C}$, respectively. The time-step was set to one hour. The weather file for the Brussels, Belgium, was used (World Meteorological Organisation station 064510) [79]. According to this weather file, the wind speed $\left(V_{10}\right)$ measured at the meteorological station site changes throughout the year between the minimum and maximum of 0 and $21.6 \mathrm{~m} / \mathrm{s}$, respectively. No correction was applied regarding the aerodynamic roughness at the building site. ESP-r has been chosen as the BES program to perform the simulation. It has been under development for more than 30 years and it has been extensively validated for many applications [80]. However, this validation has not focused specifically on the effects of $h_{c, e x t}$.

Figure 3 shows results obtained using the 12 different models for $h_{c, \text { ext }}$ implemented in ESP-r, for 3 performance indicators: annual heating energy demand, annual cooling energy demand and hourly cooling peak power demand. Considering the two groups of models for buildings with 6 to 8 storeys and for 1 storey, it is clear that the building height is an important factor in the calculation of these performance indicators. The variation in cooling energy and hourly peak power demands presented by these two groups in Figure 3 is consistent with the results in Figure 2. Higher buildings are expected to have higher convective heat losses than lower buildings (Figure 2) and consequently have a lower demand for cooling due to removal of heat from solar radiation absorbed by the facade. Considering that the building under analysis has 3 storeys, the cooling demand is expected to be in between the predictions obtained using these two groups of programs (indicated by dashed lines in the figure). Several models in Figure 3, such as that by Hagishima and Tanimoto, are far out of the range delimited by the dashed lines indicating that these models are clearly not applicable for this building. In spite of the simplifications in the models by McAdams and Jayamaha et al., these models provide cooling demands in the range defined by models for buildings with 6 to 8 storeys and for 1 storey. This apparent agreement might be a simple coincidence or it might indicate their applicability for this height of buildings. Further studies can clarify the potential applicability of models by McAdams and Jayamaha et al..

It can be inferred from Figure 3 that the cooling energy demand for the case under analysis is more sensitive to different convection models than the heating energy demand. Cooling is strongly affected by the immediate removal of solar gain by convection and radiation, while during the heating season the solar gains by opaque surfaces play a minor role in the overall heating energy demand. The minimum and maximum cooling energy demand are obtained by using the models by Nicol and Liu \& Harris (indicated in Fig. 3 by black rectangles), respectively, with deviations around $\pm 30 \%$ in relation to the average result of all BES programs. The hourly cooling peak power demand also shows significant sensitivity, with deviations around $\pm 14 \%$ in relation to the average, which can lead to over/under sizing the HVAC (Heating, Ventilation and Air Conditioning) system in the building. Deviations in heating energy demand are around $\pm 6 \%$ in relation to the average.

The large variation observed in BES results highlights the importance of using an appropriate convection model for simulations of a specific building, certainly for calculating cooling demands and related important performance indicators such as indoor temperatures, indoor relatively humidity, thermal comfort, etc.

\section{Discussion}

The information provided in this paper has highlighted a number of important but still unsolved issues in the calculation of convective heat transfer coefficients of external building surfaces. Some of these issues are discussed below. 


\subsection{Reliability of $\boldsymbol{h}_{c, \text { ext }}$ models}

The first, and probably the most important issue is the reliability of $h_{c, e x t}$ calculations. At present, it is rather difficult to attest the actual reliability of each model, considering the heterogeneity of models, their implementation in the various BES programs presented in Section 2 and the spread in the results in Figure 2 and Figure 3. It is however possible to identify models in Table 1 with good documentation, clear applicability and requiring a few or no significant assumptions in their implementations. Section 2 describes the large assumptions involved in the 7 models based on reduced-scale experiments with flat plates without $V_{I 0}$ (see list in Table 1), from which it can be inferred that the reliability of these models is low. Also in Section 2, it is possible to identify 2 models with very few information available indicating their low reliability: the Loveday mixed model and the British standard model. Based on the results of Table 13, the paper demonstrates that 2 of the models based on full-scale experiments have missing information about the experiments carried out for the model development, suggesting reduced reliability (the models by Sturrock and by Nicol). Section 3 demonstrated that some assumptions adopted in the model by Hagishima \& Tanimoto (as implemented in ESP-r) and in the DOE-2 model can compromise their application, indicating reduced reliability. The remaining 4 models form the 2 groups identified in Section 3 as being representative of buildings with 6 to 8 storeys (ASHRAE task group and Loveday \& Taki models) and with 1 storey (models by Liu \& Harris and by MoWiTT). These can be identified as the most reliable models addressed in the present research, however it is important to keep in mind that both ASHRAE task group and Loveday \& Taki models do not use $V_{l 0}$, and therefore they adopt assumptions regarding the reference wind speed.

Results presented in this paper demonstrate the necessity of high-quality data for the validation of models for $h_{c, e x t}$ calculations. Unfortunately, most of the research performed so far aimed at the development of new models, rather than on the production of well-described experimental data. This practice has two main drawbacks. Firstly, the description of the experiments is often incomplete, because the focus is on the description of the model for $h_{c, e x t}$ calculation. Secondly, the publication of raw data is very rare, therefore it is impossible to analyse the performance of existing models based on these other experimental data.

\subsection{Potential of CFD for the development of $h_{c, \text { ext }}$ models}

One alternative to the current practice regarding the publication of experimental data can be observed, for example, in recently published research combining experiments with CFD simulations [11, 30]. Ref. [30] presents curves with experimental data based on $V_{10}$ and its uncertainty, however surface averaged raw data is not presented in the paper. The use of CFD for the prediction of $h_{c, e x t}$ presents an increasing gain in accuracy over the recent years, however it still requires large computational resources. However, validated CFD models have been used to developed models for the prediction of $h_{c, e x t}[11,30,31]$. These models are focused on forced convection and are still mainly accurate for windward facades. It should be noticed that, so far, none of the BES models analysed in the present research has $h_{c, e x t}$ models based on results of CFD simulations. Validated CFD simulations have been used to study in detail other phenomena related to wind flow around buildings, such as wind-driven rain [13, 75, 81], where experiments tend to be quite complex and involve large uncertainty [77]. It can be expected that CFD will be used in the near future in a similar way to study convection around buildings, particularly concerning the factors that have been addressed in a simplified way in the models analysed in this paper, which are described below.

\subsection{Sheltering effects in $h_{c, e x t}$ models}

Sheltering by other buildings is not properly addressed by any of the models analysed in this paper. Predictive models for other aspects of wind flow around building, such as wind pressure at the facades, have specific parameters describing the size, amount and sometimes the position of the surrounding buildings [34]. This is not the case with $h_{c, e x t}$ models, and research is required in this direction, preferably with $V_{10}$-based reduced-scale experiments with building models in boundary-layer wind tunnel or with CFD simulations, where different configurations can be tested and their effects systematically analysed.

\subsection{Natural and forced convection in $h_{c, e x t}$ models}

Natural convection is only taken into account by 5 models where the surface to air temperature difference is included as a parameter (see Table 12). It is also noticeable that these models adopt rather different approaches to define the ratio between natural and forced convection. The calculation of this ratio is very complex in full-scale experiments, but CFD simulations can provide useful information regarding the magnitude of the natural and 
forced convection components. It should be noted that under natural convection, the convective transfer coefficients are generally rather low compared to forced convection, when the magnitude of the boundary layer resistance is smaller than under natural convection.

In other wind related phenomena, such as natural ventilation, the ratio between buoyancy and forced convection has been studied based on non-dimensional numbers, such as the Archimedes or the Grashof numbers [82]. Recent studies investigate mixed convection in wind flow problems [83-85], but, to the best of our knowledge, this approach has not yet been pursued for the $\mathrm{h}_{\mathrm{c}, \text { ext }}$ models implemented in BES programs in this study. In addition, note that in heat transfer literature, forced, natural or mixed convective heat transfer coefficients are usually expressed in dimensionless form (Nusselt number) for laminar or turbulent flow. However, in the BES programs and source documents underlying this review, this approach is not used and all models are expressed in terms of the $\mathrm{h}_{\mathrm{c}, \mathrm{ext}}$.

\subsection{Radiation in $h_{c, \text { ext }}$ models}

Experiments to obtain $h_{c, \text { ext }}$ values pose a number of challenges, as $h_{c, \text { ext }}$ cannot be directly measured. Most experimental setups to measure $h_{c, \text { ext }}$ adopt heat flux sensors installed on the building facade. The sensor measures combined convective and long-wave radiative heat fluxes (usually experiments are conducted at night to avoid the short-wave radiation component). The radiative component is subtracted during data postprocessing. Estimation of the radiative component is subject to large uncertainty, as it is calculated based on measured sky temperature and surface temperature, and the assumed emissivity of the surface. The radiative component is also constantly affected by variations in sky temperature due to changes in the cloud cover during the measurement. These variations increase the complexity of post-processing, as they are superimposed on the variability of wind conditions. Experiments to obtain $h_{c, e x t}$ rarely address the propagation of uncertainties in the measurement, masking the complexity in this sort of experiments.

\subsection{Surface roughness in $h_{c, \text { ext }}$ models}

Facade roughness is taken into account by 6 models (see Table 12), but the importance attributed to this factor varies largely between models. The model by McAdams shows an increase in $h_{c, \text { ext }}$ of 6 to $10 \%$ for rough surfaces when compares smooth ones, while DOE-2 model shows differences up to $117 \%$. This clearly points to the need for further research on the role of roughness in the convection at building exterior surfaces. However, in this case it is rather difficult to perform CFD simulations or reduced-scale experiments. In the case of CFD, accurate results of convective heat transfer problems usually demand the used of low-Reynolds modelling in the solid-liquid interface [11]. Low-Reynolds modelling would require the modelling of individual roughness elements, which would involve an enormous amount of work and computational resources [11]. For reducedscale experiments, similarity constraints are the main limitation.

\subsection{Surface-averaged and local values in $h_{c, e x t}$ models}

In the implementations in BES programs analysed in this paper, all $h_{c, \text { ext }}$ models are assumed to provide surfaceaveraged values of $h_{c, e x t}$, which can be applied for all thermal zones of the building (such as rooms, etc) and for all external building envelope elements sharing the same orientation regarding the wind. This assumption is in line the development of $h_{c, \text { ext }}$ models reported in this paper. However, this is not the case in models implemented in EnergyPlus (see Table 1). EnergyPlus uses $V_{z}$ instead of $V_{10}$ as reference wind speed, which leads to different $h_{c, e x t}$ for zones at different height-above-the-ground. This practice provides some sort of discretisation in the values of $h_{c, \text { ext }}$ over the facade (the higher the position of the zone above the ground, the higher the $h_{c, \text { ext }}$ ). However, this practice is not based on experiments, being an assumption adopted in the implementation of $h_{c, e x t}$ models in EnergyPlus. In fact the use of surface-averaged $h_{c, \text { ext }}$ is a major assumption because $h_{c, \text { ext }}$ shows large variations over the facade [11]. This variation is consistent with other phenomena related to wind flow around buildings, such as wind-driven rain and wind pressure $[11,12,34,75,86]$. Regarding wind pressure, it has been demonstrated that the use of surface-averaged values may lead to error up to $400 \%$ in the calculated flow rate [87]. Future research should investigate the importance of local $h_{c, \text { ext }}$, in the calculation of relevant performance indicators for buildings.

Surface dimension is another relevant aspect related to local values of $h_{c, \text { ext }}$. Surface dimension is important in convection problems, because the thermal boundary layer thickness grows over the surface, reducing the convective heat transfer [14]. In BES, each thermal zone is analysed separately regarding convection, and the dimensions of each surface may be used as input in the calculation. The surface dimension is only taken to account by the BLAST model and related models, in spite of its recognized importance in convection problems 
[14]. Surface dimension is also important in forced convection problems due to the high heat transfer found near edges where flow separation occurs. Variations of $h_{c, \text { ext }}$ due to the surface dimensions should be addressed by future studies.

\subsection{Relation between $h_{c, \text { ext }}$ values and building height}

The present paper provides several indications that $h_{c, \text { ext }}$ increases with building height. As described in the previous section, for example, models implemented in EnergyPlus use $V_{z}$ as reference wind speed. This implies that the higher the building, the higher $V_{z}$ and the higher $h_{c, \text { ext }}$. Another example is provided by the results in Figure 2, which show higher $h_{c, e x t}$ in models developed using experiments in buildings with 6 to 8 storeys (ASHRAE task group and Loveday \& Taki models) than in models for 1 storey buildings (models by Liu \& Harris and by MoWiTT). The increase in $h_{c, \text { ext }}$ with the building height is consistent with the increase in wind speed with height in the atmospheric boundary layer and with the usually larger exposure for high buildings. However, it contradicts the behaviour observed in other phenomena related to wind flow around buildings for cases with wind direction orthogonal to the surface. It has been demonstrated that, for wind direction orthogonal to the surface, a large volume of nearly stagnated air is observed in the upstream area of higher buildings (windblocking effect), reducing the wind velocity and consequently reducing wind-driven rain in the facade [86]. The existence of wind-blocking effect in convection has not been reported so far, but it should be addressed by future studies, leading to more precise models for $h_{c, \text { ext }}$ calculation.

\subsection{Moisture in $\boldsymbol{h}_{c, \text { ext }}$ models}

As presented in Section 2.18, moisture transfer affects the heat transfer at exterior building facades. EnergyPlus is the only BES program which takes it into account to some extent, by a simplified approach. There is a clear need for a simple, but validated solution to include moisture effects in $\mathrm{h}_{\mathrm{c}, \mathrm{ext}}$ models.

\section{$5.10 \quad$ Lack of $h_{c, \text { ext }}$ models for roofs}

The last and probably the most remarkable gap that has been identified by the present paper is the lack of correlations to calculate $h_{c, \text { ext }}$ for roof surfaces. The model by Hagishima \& Tanimoto is the only one based on experiments carried out on a roof and implemented in BES. Some models, as those by Liu \& Harris and Loveday $\&$ Taki do provide correlations for $V_{R}$ but were not based on measurements of convection on the roof surfaces. Other models for $h_{c, \text { ext }}$ on roofs might be available (e.g. [83;88]), but they were not implemented in BES programs. In many BES programs, models originally developed for vertical surfaces are applied for roofs, irrespective of roof pitch and orientation. For some applications, such as tall buildings, heat losses from the roof do not play a major role, however this is not the case for many other buildings such as detached houses, warehouses and large commercial centres. It should be pointed out that convective heat transfer calculations for roofs represent some of the most complex problems in wind flow around buildings, due to the variety in their geometry and the complex flow patterns in the separated regions above the roofs [24, 89-93].

\section{Conclusions}

This paper has provided an extensive review of models to calculate exterior convective heat transfer coefficients $\left(h_{c, \text { ext }}\right)$ implemented in commonly used building energy simulation (BES) programs and their impact on heating and cooling energy demand. The main conclusions are:

- $\quad$ The model by McAdams is the most common model in BES programs to predict $h_{c, \text { ext }}$.

- $\quad$ Most programs rely on a single model to predict $h_{c, \text { ext }}$ for all types of buildings.

- Many assumptions are adopted in the implementation of models based on definitions of the reference wind speed which are not consistent with that in BES weather files, such $V_{f}, V_{R}$ and $V_{l o c}$, increasing the uncertainty in the results obtained with these models. When additional and accurate information on the relation between these reference wind speed definitions cannot be obtained, the use of these models should therefore be avoided.

- $\quad$ From the models analysed in this paper, the models by the ASHRAE task group and by Loveday \& Taki are recommended for buildings with 6 to 8 storeys.

- $\quad$ From the models analysed in this paper, the models by models by Liu \& Harris and by MoWiTT are recommended for buildings with 1 storey.

- Other models analysed in this paper have limited applicability, due to particularities in their experimental setups or due to lack of information about their scope. 
- The use of different models leads to deviations up to $\pm 30 \%$ in the yearly cooling energy demand for a simple cubic building (in relation to the average result).

- Future studies are necessary to bring a better understanding to the role of: sheltering, natural and force convection, roughness of the surface, dimensions of the surface, surface-averaged and local heat transfer coefficients, building height and wind-blocking effect.

- There is a lack of models to calculate convective heat transfer coefficient for roofs in the BES programs evaluated in this paper.

The large uncertainty associated with the use of different $h_{c, \text { ext }}$ models highlights the importance of using an appropriate convection model for simulations of a specific building, certainly for calculating cooling demands and related important performance indicators such as indoor temperatures, indoor relatively humidity, thermal comfort, etc. Future studies should address the importance of factors affecting $h_{c, \text { ext }}$ values for the evaluation of a variety of performance indicators in building performance simulation.

\section{Acknowledgements}

This research has been funded by the "Institute for the Promotion of Innovation by Science and Technology in Flanders" (IWT-Vlaanderen) as part of the SBO-project IWT 050154 'Heat, Air and Moisture Performance Engineering: a whole building approach'. This financial contribution is gratefully acknowledged.

\section{References}

[1] J.L.M. Hensen, R. Lamberts, C.O.R. Negrao, A view of energy and building performance simulation at the start of the third millennium, Energy and Buildings, 34 (2002) 853-855.

[2] A.M. Malkawi, G. Augenbroe, Advanced building simulation, in, Spon Press, New York, 2003.

[3] W.C. Turner, S. Doty, Energy management handbook, 7th ed., Fairmont, Lilburn, 2009.

[4] J.L.M. Hensen, R. Lamberts, Building Performance Simulation for Design and Operation, in, Routledge, London, 2011, pp. 277-311.

[5] D.B. Crawley, J.W. Hand, M. Kummert, B.T. Griffith, Contrasting the capabilities of building energy performance simulation programs, Building and Environment, 43 (2008) 661-673.

[6] J.A. Clarke, Energy simulation in building design, Butterworth-Heinemann, Oxford, 2001.

[7] P.I. Cooper, The effect of inclination on the heat loss from flat-plate solar collectors, Solar Energy, 27 (1981) 413-420.

[8] J.A. Palyvos, A survey of wind convection coefficient correlations for building envelope energy systems' modeling, Applied Thermal Engineering, 28 (2008) 801-808.

[9] R.D. Clear, L. Gartland, F.C. Winkelmann, An empirical correlation for the outside convective air-film coefficient for horizontal roofs, Energy and Buildings, 35 (2003) 797-811.

[10] D. Aelenei, F.M.A. Henriques, Analysis of the condensation risk on exterior surface of building envelopes, Energy and Buildings, 40 (2008) 1866-1871.

[11] B. Blocken, T. Defraeye, D. Derome, J. Carmeliet, High-resolution CFD simulations for forced convective heat transfer coefficients at the facade of a low-rise building, Building and Environment, 44 (2009) 23962412.

[12] B. Blocken, S. Roels, J. Carmeliet, A combined CFD-HAM approach for wind-driven rain on building facades, Journal of Wind Engineering and Industrial Aerodynamics, 95 (2007) 585-607.

[13] M. Abuku, B. Blocken, S. Roels, Moisture response of building facades to wind-driven rain: Field measurements compared with numerical simulations, Journal of Wind Engineering and Industrial Aerodynamics, 97 (2009) 197-207.

[14] F.P. Incropera, D.P. DeWitt, Fundamentals of heat and mass transfer, 5th ed., Wiley, Chichester, 2001.

[15] J.H. Lienhard IV, J.H. Lienhard V, A heat transfer textbook, 3rd ed., Phlogiston Press, Cambridge Massachusetts, 2005.

[16] T. Stathopoulos, H. Wu, Generic models for pedestrian-level winds in built-up regions, Journal of Wind Engineering and Industrial Aerodynamics, 54-55 (1995) 515-525.

[17] S. Murakami, Computational Wind Engineering, Journal of Wind Engineering and Industrial Aerodynamics, 36 (1990) 517-538.

[18] R. Yoshie, A. Mochida, Y. Tominaga, H. Kataoka, K. Harimoto, T. Nozu, T. Shirasawa, Cooperative project for CFD prediction of pedestrian wind environment in the Architectural Institute of Japan, Journal of Wind Engineering and Industrial Aerodynamics, 95 (2007) 1551-1578. 
[19] T. van Hooff, B. Blocken, Coupled urban wind flow and indoor natural ventilation modelling on a highresolution grid: A case study for the Amsterdam ArenA stadium, Environmental Modelling \& Software, 25 (2010) 51-65.

[20] P. Gousseau, B. Blocken, T. Stathopoulos, G.J.F.v. Heijst, CFD simulation of near-field pollutant dispersion on a high-resolution grid: a case study by LES and RANS for a building group in downtown Montreal, Atmospheric Environment, 45 (2011) 428-438.

[21] T. van Hooff, B. Blocken, On the effect of wind direction and urban surroundings on natural ventilation of a large semi-enclosed stadium, Computers \& Fluids, 39 (2010) 1146-1155.

[22] B. Blocken, W.D. Janssen, T. van Hooff, CFD simulation for pedestrian wind comfort and wind safety in urban areas: General decision framework and case study for the Eindhoven University campus, Environmental Modelling \&amp; Software, 30 (2012) 15-34.

[23] P. Moonen, T. Defraeye, V. Dorer, B. Blocken, J. Carmeliet, Urban physics: effect of the microclimate on comfort, health and energy demand, Frontiers of Architectural Research, In press (2012).

[24] B. Blocken, T. Stathopoulos, J. Carmeliet, J.L.M. Hensen, Application of computational fluid dynamics in building performance simulation for the outdoor environment: an overview, Journal of Building Performance Simulation, 4 (2011) 157-184.

[25] B. Blocken, T. Stathopoulos, J. Carmeliet, CFD simulation of the atmospheric boundary layer: wall function problems, Atmospheric Environment, 41 (2007) 238-252.

[26] J. Wieringa, Updating the Davenport Roughness Classification, Journal of Wind Engineering and Industrial Aerodynamics, 41 (1992) 357-368.

[27] J. Franke, A. Hellsten, H. Schlünzen, B. Carissimo, Best practice guideline for the CFD simulation of flows in the urban environment, COST Office Brussels, ISBN 3-00-018312-4, 2007.

[28] R. Cai, N. Zhang, Explicit analytical solutions of 2-D laminar natural convection, International Journal of Heat and Mass Transfer, 46 (2003) 931-934.

[29] M. Massabó, R. Cianci, O. Paladino, Some analytical solutions for two-dimensional convection-dispersion equation in cylindrical geometry, Environmental Modelling \& Software, 21 (2006) 681-688.

[30] T. Defraeye, B. Blocken, J. Carmeliet, CFD analysis of convective heat transfer at the surfaces of a cube immersed in a turbulent boundary layer, International Journal of Heat and Mass Transfer, 53 (2010) $297-$ 308.

[31] T. Defraeye, B. Blocken, J. Carmeliet, Convective heat transfer coefficients for exterior building surfaces: Existing correlations and CFD modelling, Energy Conversion and Management, 52 (2011) 512-522.

[32] P. Karava, C.M. Jubayer, E. Savory, Numerical modelling of forced convective heat transfer from the inclined windward roof of a lowrise building with application to Photovoltaic/Thermal systems, Applied Thermal Engineering, 31 (2011) 1950-1963.

[33] T. Defraeye, B. Blocken, J. Carmeliet, An adjusted temperature wall function for turbulent forced convective heat transfer for bluff bodies in the atmospheric boundary layer, Building and Environment, 46 (2011) 2130-2141.

[34] D. Cóstola, B. Blocken, J.L.M. Hensen, Overview of pressure coefficient data in building energy simulation and airflow network programs, Building and Environment, 44 (2009) 2027-2036.

[35] http://www.esru.strath.ac.uk/Programs/ESP-r.htm (Retrieved on 4-April-2009).

[36] EnergyPlus, EnergyPlus Engineering Reference - The Reference to EnergyPlus Calculations, 2007.

[37] Integrated Environmental Solutions IES, Calculation Methods - <Virtual Environment> 5.6, n.d.

[38] http://www.equa.se/ice/intro.html (Retrieved on 4-April-2009).

[39] EDSL, TAS Theory, EDSL, n.d.

[40] http://www.trnsys.com/ (Retrieved on 4-April-2009).

[41] M. Deru, R. Judkoff, P. Torcellini, SUNREL Technical Reference Manual, NREL, Golden, 2002.

[42] W.H. McAdams, Heat transmission, McGraw-Hill Kogakusha, Tokyo, Japan, 1954.

[43] W. Jürges, Der wärmeübergang an einer ebenen wand (heat transfer at a plane wall), Gesundh.-Ing., Beiheft Nr. 19 zum (1924).

[44] R. Judkoff, J. Neymark, International Energy Agency Building Energy Simulation Test (BESTEST) and diagnostic method. Report NREL/TP-472-6231. Golden: NREL, 1995.

[45] J.H. Klems, S. Selkowitz, S. Horowitz, A mobile facility for measuring net energy performance of windows and skylights, in: Proceedings of the CIB W67 3rd International Symposium on Energy Conservation in the Built Environment, Vol. 3, Dublin, Ireland, 1982, pp. p.3.1.

[46] B. Blocken, T. Stathopoulos, J. Carmeliet, A numerical study on the existence of the Venturi-effect in passages between perpendicular buildings, Journal of Engineering Mechanics - ASCE, 134 (2008) 10211028 . 
[47] ASHRAE, Procedure for determining heating and cooling loads for computerising energy calculations. Algorithms for building heat transfer subroutines, ASHRAE, New York, 1975.

[48] Chartered Institute of Building Services (CIBS) Guide Book A, Section A3, CIBS, London, 1979.

[49] G.N. Walton, Passive solar extension of the Building Loads Analysis and System Thermodynamics (BLAST) program, in, United States Army Construction Engineering Research Laboratory, Champaign, IL., 1981.

[50] T.M. McClellan, C.O. Pedersen, Investigation of outside heat balance models for use in a heat balance cooling load calculation procedure ASHRAE Transactions, 103 (2) (1997) 469-484.

[51] E.M. Sparrow, J.W. Ramsey, E.A. Mass, Effect of finite width on heat transfer and fluid flow about an inclined rectangular plate, Journal of Heat Transfer, 101 (1979) 204.

[52] R.J. Cole, N.S. Sturrock, The convective heat exchange at the external surface of buildings, Building and Environment, 12 (1977) 207-214.

[53] ASHRAE, ASHRAE Handbook - Fundamentals, Atlanta, GA, USA, 1981.

[54] G.N. Walton, Thermal analysis research program reference manual, NBSSIR 83-2655, National Bureau of Standards, (1983).

[55] ASHRAE, ASHRAE Handbook - Fundamentals, Atlanta, GA, USA, 2005.

[56] T. Kusuda, NBSLD, the computer program for heating and cooling loads in buildings, NBS building science series 69, National Bureau of Standards, Washington, DC, 1976.

[57] F.B. Rowley, A.B. Algren, J.L. Blackshaw, Surface conductance as affected by air velocity, temperature and character of surface, ASHRAE Transactions, 36 (1930) 429.

[58] F.B. Rowley, W.A. Eckley, Surface coefficients as affected by direction of wind, ASHRAE Transactions, 38 (1932) 33-46.

[59] S.E.G. Jayamaha, N.E. Wijeysundera, S.K. Chou, Measurement of the heat transfer coefficient for walls, Building and Environment, 31 (1996) 399-407.

[60] N.S. Sturrock, Localised boundary layer heat transfer from external building surfaces, PhD thesis, in, University of Liverpool, 1971.

[61] S. Sharples, Full-scale measurements of convective energy losses from exterior building surfaces, Building and Environment, 19 (1984) 31-39.

[62] N. Ito, K. Kimura, J. Oka, A field experiment study on the convective heat transfer coefficient on the exterior surface of a building, ASHRAE Transactions, 78, Part 2 (1972) 184.

[63] K. Nicol, The energy balance of an exterior window surface, Inuvik, N.W.T., Canada, Building and Environment, 12 (1977) 215-219.

[64] D.L. Loveday, A.H. Taki, Convective heat transfer coefficients at a plane surface on a full-scale building facade, International Journal of Heat and Mass Transfer, 39 (1996) 1729-1742.

[65] A. Hagishima, J. Tanimoto, Field measurements for estimating the convective heat transfer coefficient at building surfaces, Building and Environment, 38 (2003) 873-881.

[66] M. Yazdanian, J.H. Klems, Measurement of the exterior convective film coefficient for windows in low-rise buildings, ASHRAE Transactions, Vol. 100, Part 1 (1994) 1087.

[67] Lawrence Berkeley Laboratory (LBL). DOE2.1E-053 source code, 1994.

[68] Y. Liu, D.J. Harris, Full-scale measurements of convective coefficient on external surface of a low-rise building in sheltered conditions, Building and Environment, 42 (2007) 2718-2736.

[69] German version EN ISO 6946: 1996 + A1: 2003, Building components and building elements. Thermal resistance and thermal transmittance. Calculation method., 1997.

[70] H. Breesch, A. Janssens, Performance evaluation of passive cooling in office buildings based on uncertainty and sensitivity analysis, Solar Energy, 84 (2010) 1453-1467.

[71] E. Djunaedy, J.L.M. Hensen, M. Loomans, External coupling between CFD and energy simulation: implementation and validation, ASHRAE Transactions, American Society of Heating, Refrigerating, and Air-Conditioning Engineers, 111 (2005) 612-624.

[72] Z.J. Zhai, Q.Y. Chen, Sensitivity analysis and application guides for integrated building energy and CFD simulation, Energy and Buildings, 38 (2006) 1060-1068.

[73] M. Abuku, H. Janssen, S. Roels, Impact of wind-driven rain on historic brick wall buildings in a moderately cold and humid climate: Numerical analyses of mould growth risk, indoor climate and energy consumption, Energy and Buildings, 41 (2009) 101-110.

[74] H. Janssen, B. Blocken, J. Carmeliet, Conservative modelling of the moisture and heat transfer in building components under atmospheric excitation, International Journal of Heat and Mass Transfer, 50 (2007) 1128-1140.

[75] B. Blocken, J. Carmeliet, A review of wind-driven rain research in building science, Journal of Wind Engineering and Industrial Aerodynamics, 92 (2004) 1079-1130. 
[76] B. Blocken, J. Carmeliet, High-resolution wind-driven rain measurements on a low-rise buildingexperimental data for model development and model validation, Journal of Wind Engineering and Industrial Aerodynamics, 93 (2005) 905-928.

[77] B. Blocken, J. Carmeliet, On the accuracy of wind-driven rain measurements on buildings, Building and Environment, 41 (2006) 1798-1810.

[78] Y. Tominaga, A. Mochida, R. Yoshie, H. Kataoka, T. Nozu, M. Yoshikawa, T. Shirasawa, AIJ guidelines for practical applications of CFD to pedestrian wind environment around buildings, Journal of Wind Engineering and Industrial Aerodynamics, 96 (2008) 1749-1761.

[79] ASHRAE, International Weather for Energy Calculations (IWEC Weather Files) Users Manual and CDROM, ASHRAE, Atlanta, 2001.

[80] P. Strachan, ESP-r: Summary of validation studies, ESRU technical report, Glasgow, 2000.

[81] B. Blocken, J. Carmeliet, Validation of CFD simulations of wind-driven rain on a low-rise building facade, Building and Environment, 42 (2007) 2530-2548.

[82] D. Etheridge, M. Sandberg, Building Ventilation: Theory and Measuremen, John Wiley \& Sons, Chichester, 1996.

[83] P. Karava,C. Jubayer, E.Savory, S. Li, Effect of incident flow conditions on convective heat transfer from the inclined windward roof of a low-rise building with application to photovoltaic-thermal systems. Journal of Wind Engineering \& Industrial Aerodynamics 104-106 (2012) 428-438.

[84] A. Nottrott, S. Onomura, A. Inagaki, M. Kanda, J. Kleissl, Convective heat transfer on leeward building walls in an urban environment: Measurements in an outdoor scale model. International Journal of Heat and Mass Transfer 54 (2011) 3128-3138.

[85]T. Defraeye, B. Blocken, J. Carmeliet, CFD simulation of heat transfer at surface of bluff bodies in turbulent boundary layers: evaluation of a forced-convective temperature wall function for mixed convection. Journal of Wind Engineering and Industrial Aerodynamics 104-106 (2012) 439-446.

[86] B. Blocken, J. Carmeliet, The influence of the wind-blocking effect by a building on its wind-driven rain exposure, Journal of Wind Engineering and Industrial Aerodynamics, 94 (2006) 101-127.

[87] D. Cóstola, B. Blocken, M. Ohba, J.L.M. Hensen, Uncertainty in airflow rate calculations due to the use of surface-averaged pressure coefficients, Energy and Buildings, 42 (2010) 881-888.

[88] S. Kumar, C. Mullick, Wind heat transfer coefficient in solar collectors in outdoor conditions. Solar Energy 84 (2010) 956-963.

[88] R.P. Hoxey, P.J. Richards, Flow patterns and pressure field around a full-scale building, Journal of Wind Engineering and Industrial Aerodynamics, 50 (1993) 203-212.

[89] P.J. Richards, R.P. Hoxey, Flow reattachment on the roof of a 6\&\#xa0;m cube, Journal of Wind Engineering and Industrial Aerodynamics, 94 (2006) 77-99.

[90] T. Stathopoulos, Computational wind engineering: Past achievements and future challenges, Journal of Wind Engineering and Industrial Aerodynamics, 67-68 (1997) 509-532.

[91] P.J. Richards, R.P. Hoxey, B.D. Connell, D.P. Lander, Wind-tunnel modelling of the Silsoe Cube, Journal of Wind Engineering and Industrial Aerodynamics, 95 (2007) 1384-1399.

[92] Y. Tominaga, A. Mochida, S. Murakami, S. Sawaki, Comparison of various revised k-E models and LES applied to flow around a high-rise building model with 1:1:2 shape placed within the surface boundary layer, Journal of Wind Engineering and Industrial Aerodynamics, 96 (2008) 389-411. 


\section{Nomenclature}

\section{Roman symbols}

A Area of the surface $\left(\mathrm{m}^{2}\right)$

a Coefficient $\left(\mathrm{W} / \mathrm{m}^{2} \mathrm{~K}(\mathrm{~m} / \mathrm{s})^{\mathrm{b}}\right)$

b Exponent (-)

$c \quad$ Wind speed profile exponent at the building site

$c_{f} \quad$ Wind speed profile exponent at the weather station

$C_{t} \quad$ Turbulent natural convection constant $\left(\mathrm{W} / \mathrm{m}^{2} \mathrm{~K}^{4 / 3}\right)$

$h_{c, e x t} \quad$ External convective heat transfer coefficient $(\mathrm{W} / \mathrm{m} 2 \mathrm{~K})$

$h_{\text {ext }} \quad$ Combined radiative and convective external heat transfer coefficient $\left(\mathrm{W} / \mathrm{m}^{2} \mathrm{~K}\right)$

$h_{c, f o r} \quad$ Convective heat transfer coefficient related to forced convection regime $\left(\mathrm{W} / \mathrm{m}^{2} \mathrm{~K}\right)$

$h_{c, \text { nat }} \quad$ Convective heat transfer coefficient related to natural convection regime $\left(\mathrm{W} / \mathrm{m}^{2} \mathrm{~K}\right)$

$P \quad$ Perimeter of the surface $(\mathrm{m})$

$q_{c} \quad$ Convective heat flux $\left(\mathrm{W} / \mathrm{m}^{2}\right)$

$q_{r} \quad$ Long-wave radiative heat flux $\left(\mathrm{W} / \mathrm{m}^{2}\right)$

$S \quad$ Absorbed short-wave radiative heat flux $\left(\mathrm{W} / \mathrm{m}^{2}\right)$

$T_{s} \quad$ Surface temperature $(\mathrm{K})$

$T_{a} \quad$ Air temperature (K)

$T_{\text {sky }} \quad$ Sky effective temperature (K)

$T_{\text {gnd }} \quad$ Effective temperature of the ground surface $(\mathrm{K})$

$R_{f} \quad$ Surface roughness multiplier

$V_{R} \quad$ Wind speed above the roof $(\mathrm{m} / \mathrm{s})$

$V_{f} \quad$ Free stream velocity $(\mathrm{m} / \mathrm{s})$

$V_{l o c} \quad$ Local wind speed $(\mathrm{m} / \mathrm{s})$

$V_{10} \quad$ Wind speed measured at weather station $10 \mathrm{~m}$ above the ground $(\mathrm{m} / \mathrm{s})$

$V \quad$ Wind speed $(\mathrm{m} / \mathrm{s})$

$W_{f} \quad$ Wind direction modifier

$z_{f} \quad$ Height at which standard wind speed measurements are taken at the weather station $(\mathrm{m})$

$z \quad$ Height above the ground $(\mathrm{m})$

\section{Greek symbols}

$\alpha \quad$ Wind speed profile exponent (-)

$\gamma \quad$ Wind speed profile exponent (-)

$\phi \quad$ Slope angle - the angle between the ground plane and surface plane $\left(^{\circ}\right)$

$\theta \quad$ Wind attack angle (the angle between surface normal vector and the wind direction) $\left({ }^{\circ}\right)$

$\delta \quad$ Height of the atmospheric boundary layer at the building site (m)

$\delta_{f} \quad$ Height of the atmospheric boundary layer at the weather station (m)

Acronyms

ASHRAE

BES

BLAST

CFD

CIBS

HAM

MoWiTT

NBS

TARP
American Society of Heating, Refrigerating and Air-Conditioning Engineers Building Energy Simulation

Building Loads Analysis and System Thermodynamics

Computational Fluid Dynamics

(former acronym of:) Chartered Institution of Building Services Engineers

Heat, Air and Moisture transfer

Mobile Window Thermal Test

National Bureau of Standards

Thermal Analysis Research Program 
Table 1. $h_{c, \text { ext }}$ models used in different BES programs

\begin{tabular}{|c|c|c|c|c|c|c|c|c|c|}
\hline \multirow[b]{2}{*}{ Model } & \multicolumn{7}{|c|}{ BES programs } & \multirow{2}{*}{ 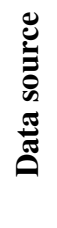 } & \multirow{2}{*}{ 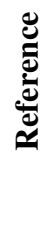 } \\
\hline & $\begin{array}{l}\dot{1} \\
\tilde{n}^{\prime}\end{array}$ & 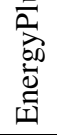 & 凹ి & 芯 & $\sum_{\Leftrightarrow}^{\infty}$ & $\begin{array}{l}\tilde{2} \\
\tilde{n} \\
\tilde{Z} \\
\tilde{y}\end{array}$ & 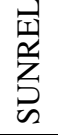 & & \\
\hline
\end{tabular}

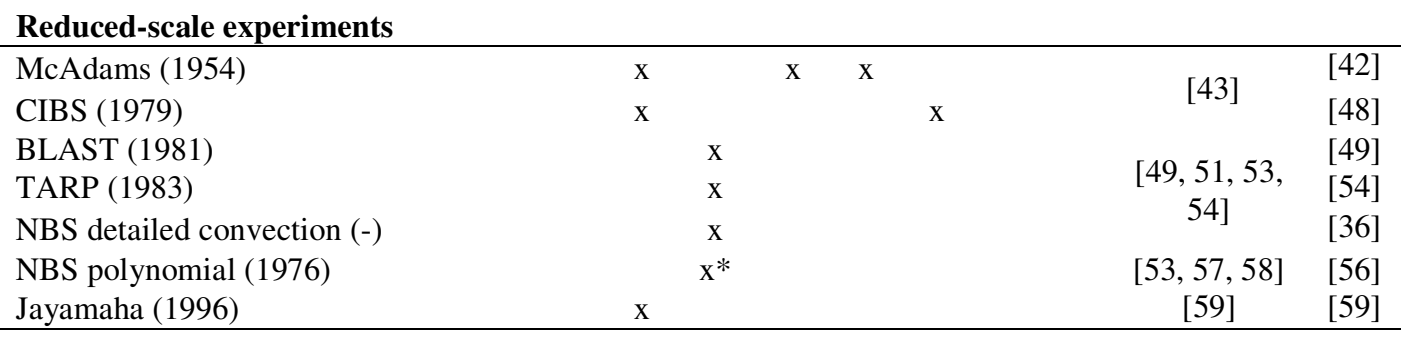

\section{On-site full-scale experiments without}

$\mathbf{V}_{10}$

Sturrock (1971) $\quad \mathrm{x} \quad$ [60] [60]

ASHRAE task group (1975) $\quad \mathrm{x} \quad$ [62] [47]

Nicol (1977)

Loveday \& Taki (1996)

Hagishima \& Tanimoto (2003)

$\begin{array}{lll}\mathrm{x} & {[63]} & {[63]} \\ \mathrm{x} & {[64]} & {[64]}\end{array}$

$\mathrm{x} \quad[65] \quad[65]$

On-site full-scale experiments with $\mathrm{V}_{10}$

\begin{tabular}{lllll} 
MoWiTT (1994) & $\mathrm{x}$ & $\mathrm{x}$ & {$[66]$} & {$[66]$} \\
DOE-2 (1994) & & $\mathrm{x}$ & {$[66]$} & {$[67]$} \\
Liu \& Harris (2007) & $\mathrm{x}$ & & {$[68]$} & {$[68]$} \\
\hline
\end{tabular}

Other models

\begin{tabular}{llll}
\hline Loveday mixed (-) & $\mathrm{x}$ & - & {$[35]$} \\
British standard (1997) & $\mathrm{x}$ & - & {$[69]$} \\
\hline
\end{tabular}

Simplified approaches

\begin{tabular}{lllllll} 
Fixed value defined by the BES program & $\mathrm{x}$ & & $\mathrm{x}^{*}$ & $\mathrm{x}$ & $\mathrm{x}^{*}$ & - \\
User-defined value/profile & $\mathrm{x}$ & $\mathrm{x}$ & & $\mathrm{x}$ & - \\
Fixed value due to rain & & $\mathrm{x}$ & & {$[36]$} \\
\hline
\end{tabular}

$\mathrm{x}^{*}$ : Combined convective and radiative coefficient

"_": Missing information

Table 2. Parameters in model by McAdams [42]

\begin{tabular}{|c|c|c|c|c|c|c|}
\hline \multirow[b]{2}{*}{ Surface type } & \multicolumn{3}{|c|}{$V_{f}<4.88 \mathrm{~m} / \mathrm{s}(16 \mathrm{ft} / \mathrm{s})$} & \multicolumn{3}{|c|}{$\begin{array}{c}4.88 \mathrm{~m} / \mathrm{s}(16 \mathrm{ft} / \mathrm{s}) \leq V_{f}< \\
30.48 \mathrm{~m} / \mathrm{s}(100 \mathrm{ft} / \mathrm{s})\end{array}$} \\
\hline & $m$ & $n$ & $p$ & $m$ & $n$ & $p$ \\
\hline Smooth & 0.99 & 0.21 & 1 & 0 & 0.50 & 0.78 \\
\hline Rough & 1.09 & 0.23 & 1 & 0 & 0.53 & 0.78 \\
\hline
\end{tabular}


Table 3. Roughness multiplier for different surface textures [49]

\begin{tabular}{lcc}
\hline Roughness index & $\boldsymbol{R}_{\boldsymbol{f}}$ & Example material \\
\hline Very rough & 2.17 & Stucco \\
Rough & 1.67 & Brick \\
Medium rough & 1.52 & Concrete \\
Medium smooth & 1.13 & Clear pine \\
Smooth & 1.11 & Smooth plaster \\
Very smooth & 1.00 & Glass \\
\hline
\end{tabular}

Table 4. Wind speed profile coefficients for different terrain types [55]

\begin{tabular}{lcc}
\hline Terrain type & $\boldsymbol{c}$ & $\boldsymbol{\delta}(\mathbf{m})$ \\
\hline 1. Large city centre & 0.33 & 460 \\
2. Urban, suburban, wooded areas & 0.22 & 370 \\
3. Open terrain & 0.14 & 270 \\
4. Flat & 0.10 & 210 \\
\hline
\end{tabular}

Table 5. Terrain roughness coefficients [49]

\begin{tabular}{clcc}
\hline Class & \multicolumn{1}{c}{ Description } & $\alpha$ & $\beta$ \\
1 & $\begin{array}{l}\text { Ocean or other body of water with at least } 5 \mathrm{~km} \text { of } \\
\text { unrestricted extension }\end{array}$ & 0.10 & 1.30 \\
2 & $\begin{array}{l}\text { Flat terrain with some isolated obstacles (buildings or trees } \\
\text { well separated from each other) }\end{array}$ & 0.15 & 1.00 \\
3 & Rural areas with low buildings, trees, etc. & 0.20 & 0.85 \\
4 & Urban, industrial, or forest area & 0.25 & 0.67 \\
5 & Centre of large city & 0.35 & 0.47 \\
\hline
\end{tabular}

Table 6. Roughness coefficients used in NBS polynomial model [57]

\begin{tabular}{lccc}
\hline Roughness Index/Example & D & E & F \\
\hline Very rough/Stucco & 11.58 & 5.894 & 0.0 \\
Rough/Brick and rough plaster & 12.49 & 4.065 & 0.028 \\
Medium rough/Concrete & 10.79 & 4.192 & 0.0 \\
Medium smooth/Clear pine & 8.23 & 4.0 & -0.057 \\
Smooth/Smooth plaster & 10.22 & 3.1 & 0.0 \\
Very smooth/Glass and white paint on pine & 8.23 & 3.33 & -0.036 \\
\hline
\end{tabular}

Table 7. Expressions used in the model by Loveday \& Taki for $h_{c, \text { ext }}$ [64]

\begin{tabular}{lcc}
\hline Surface orientation & $h_{c, \text { ext }}$ and $V_{R}$ & $\mathrm{~h}_{\mathrm{c}, \text { ext }}$ and $V_{l o c}$ \\
\hline Windward & $h_{c, \text { ext }}=2.0 V_{R}+8.91$ & $h_{c, \text { ext }}=16.15 V_{l o c}^{0.397}$ \\
Leeward & $h_{c, \text { ext }}=1.772 V_{R}+4.93$ & $h_{c, \text { ext }}=16.25 V_{l o c}^{0.503}$ \\
\hline
\end{tabular}


Table 8. Local and roof wind speed relationships in the model by Loveday \& Taki [64]

\begin{tabular}{lc}
\hline Surface orientation & Expression \\
& $V_{R}$ and $V_{l o c}$ \\
\hline Windward $\left(-90^{\circ}<\varphi<-70^{\circ}\right.$ or $\left.70^{\circ}<\varphi<90^{\circ}\right)$ & $V_{l o c}=0.2 V_{R}-0.1$ \\
Windward $\left(-70^{\circ}<\varphi<70^{\circ}\right)$ & $V_{l o c}=0.68 V_{R}-0.5$ \\
Leeward & $V_{l o c}=0.157 V_{R}-0.027$ \\
\hline
\end{tabular}

Table 9. Parameters for MoWiTT model [66]

\begin{tabular}{lccc}
\hline Surface orientation & $\boldsymbol{C}_{\boldsymbol{t}}$ & $\boldsymbol{a}$ & $\boldsymbol{b}$ \\
\hline Windward & $0.84 \pm 0.015$ & $2.38 \pm 0.036$ & $0.89 \pm 0.009$ \\
Leeward & 0.84 & $2.86 \pm 0.098$ & $0.617 \pm 0.017$ \\
\hline
\end{tabular}

Table 10. Expressions used in the model by Liu \& Harris for $h_{c, \text { ext }}$ based on different wind speed [68]

\begin{tabular}{lccc}
\hline Surface orientation & $h_{c, e x t}$ and $V_{l o c}$ & $\begin{array}{c}\text { Expression } \\
h_{c, e x t} \text { and } V_{R}\end{array}$ & $h_{c, e x t}$ and $V_{l 0}$ \\
\hline Windward & $h_{c, e x t}=6.31 V_{l o c}+3.32$ & $h_{c, e x t}=2.08 V_{R}+2.97$ & $h_{c, e x t}=1.53 V_{10}+1.43$ \\
Leeward & $h_{c, e x t}=5.03 V_{l o c}+3.19$ & $h_{c, e x t}=1.57 V_{R}+2.64$ & $h_{c, e x t}=0.90 V_{10}+3.28$ \\
\hline
\end{tabular}

Table 11. Expressions used in the model by Liu \& Harris for $V_{l l o c}$ and $V_{R}$ as function of $V_{10}$ [68]

\begin{tabular}{|c|c|c|}
\hline \multirow{2}{*}{ Surface orientation } & \multicolumn{2}{|c|}{ Expression } \\
\hline & $V_{l 0}$ and $V_{l o c}$ & $V_{I 0}$ and $V_{R}$ \\
\hline Windward & $V_{l o c}=0.26 V_{10}+0.06$ & $V_{R}=0.55 V_{10}+0.67$ \\
\hline Leeward & $V_{l o c}=0.19 V_{10}+0.14$ & $V_{R}=0.43 V_{10}+0.24$ \\
\hline
\end{tabular}


Table 12. Comparison of convection model completeness

\begin{tabular}{|c|c|c|c|c|c|c|c|c|c|}
\hline \multirow[b]{2}{*}{ Model } & \multicolumn{9}{|c|}{ Influencing factors } \\
\hline & 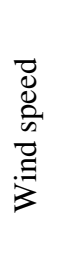 & 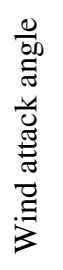 & 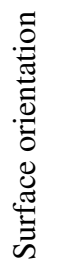 & 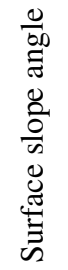 & 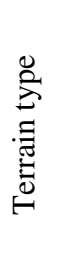 & 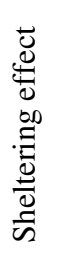 & 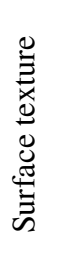 & 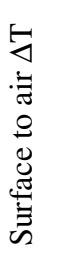 & 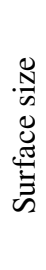 \\
\hline \multicolumn{10}{|l|}{ Reduced experiments } \\
\hline McAdams (1954) & $x^{1}$ & $\mathrm{x}^{2}$ & $\mathrm{X}$ & & & & $\mathrm{x}^{3}$ & & \\
\hline CIBS (1979) & $\mathrm{x}$ & & & & & $\mathrm{x}$ & & & \\
\hline BLAST (1981) & $\mathrm{x}$ & & $\mathrm{x}$ & $\mathrm{x}$ & $\mathrm{X}$ & & $\mathrm{x}$ & $\mathrm{x}$ & $\mathrm{x}$ \\
\hline TARP (1983) & $\mathrm{x}$ & & $\mathrm{x}$ & $\mathrm{x}$ & $\mathrm{x}$ & & $\mathrm{x}$ & $\mathrm{x}$ & $\mathrm{x}$ \\
\hline NBS detailed convection (-) & $\mathrm{x}$ & & $\mathrm{x}$ & $\mathrm{x}$ & $\mathrm{x}$ & & $\mathrm{x}$ & $\mathrm{x}$ & $\mathrm{x}$ \\
\hline NBS polynomial (1976) & $\mathrm{x}$ & & & & $x^{5}$ & & $\mathrm{x}$ & & \\
\hline Jayamaha (1996) & $\mathrm{x}$ & & & & & & & & \\
\hline \multicolumn{10}{|c|}{ Full-scale experiments without $V_{10}$} \\
\hline Sturrock (1971) & $\mathrm{x}$ & & & & & $\mathrm{x}^{4}$ & & & \\
\hline ASHRAE task group (1975) & $\mathrm{x}$ & & $\mathrm{x}$ & & & & & & \\
\hline Nicol (1977) & $\mathrm{x}$ & & & & & & & & \\
\hline Loveday \& Taki (1996) & $\mathrm{x}$ & & $\mathrm{x}$ & & & & & & \\
\hline Hagishima \& Tanimoto (2003) & $\mathrm{x}$ & & & $x^{6}$ & & & & & \\
\hline \multicolumn{10}{|l|}{ Full-scale experiments with $V_{10}$} \\
\hline MoWiTT (1994) & $\mathrm{x}$ & & $\mathrm{x}$ & & $\mathrm{x}$ & & & $\mathrm{x}$ & \\
\hline DOE-2 (1994) & $\mathrm{x}$ & & $\mathrm{x}$ & & $\mathrm{x}$ & & $\mathrm{x}$ & $\mathrm{x}$ & \\
\hline Liu \& Harris (2007) & $\mathrm{x}$ & & $\mathrm{x}$ & & & & & & \\
\hline \multicolumn{10}{|l|}{ Other models } \\
\hline Loveday mixed & $\mathrm{x}$ & & & & & & & & \\
\hline British standard & $\mathrm{x}$ & & & & & & & & \\
\hline $\begin{array}{l}\text { 1. ESP-r and IDA have an algor } \\
\text { 2. In ESP-r wind attack angle is } \\
\text { not clearly addressed in the doct } \\
\text { 3. In IDA the expression for rou } \\
\text { expression for smooth surfaces } \\
\text { 4. In ESP-r the expression for ur } \\
\text { 5. As implemented in EnergyPl } \\
\text { 6. Only horizontal and vertical s } \\
\text { sloped surfaces. }\end{array}$ & $\begin{array}{l}\text { adju } \\
\text { ato a } \\
\text { ion. } \\
\text { aces } \\
\text { derec } \\
\text { ed st } \\
\text { are }\end{array}$ & $\begin{array}{l}\text { loca } \\
\text { count } \\
\text { cons } \\
\text { In E } \\
\text { faces }\end{array}$ & $\begin{array}{l}\text { velo } \\
\text { but i } \\
\text { dere } \\
\text { P-r i } \\
\text { is im } \\
\text { to ac }\end{array}$ & $\begin{array}{l}\text { ity b } \\
\text { IES } \\
\text {, whi } \\
\text { is no } \\
\text { leme }\end{array}$ & $\begin{array}{l}\text { IES } \\
\text { nd ID } \\
\text { in I } \\
\text { clear } \\
\text { ted. } \\
\text { n this }\end{array}$ & $\begin{array}{l}\text { Lees } 1 \\
\text { A thi } \\
\text { S the }\end{array}$ & issue & & \\
\hline
\end{tabular}


Table 13. Information on experimental setups in different convection models

\begin{tabular}{|c|c|c|c|c|c|c|c|c|c|}
\hline \multirow{3}{*}{ Model } & \multicolumn{9}{|c|}{ Experimental setup } \\
\hline & \multicolumn{3}{|c|}{ 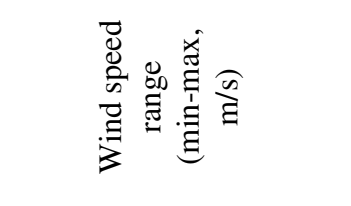 } & \multicolumn{2}{|c|}{ 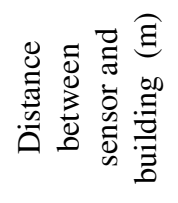 } & \multirow{2}{*}{ 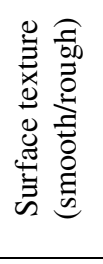 } & \multirow{2}{*}{ 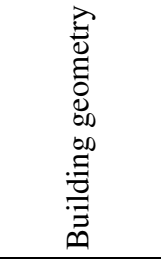 } & \multirow{2}{*}{ 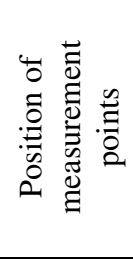 } & \multirow[t]{2}{*}{ 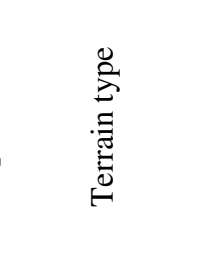 } \\
\hline & $V_{l o c}$ & $V_{10}$ & $V_{R}$ & $V_{l o c}$ & $V_{R}$ & & & & \\
\hline \multicolumn{10}{|l|}{ Reduced-scale experiments } \\
\hline McAdams (1954) & n.a. & n.a. & n.a. & n.a. & n.a. & $\mathrm{s} / \mathrm{r}$ & flat plate & n.a. & n.a. \\
\hline \multicolumn{10}{|l|}{$\begin{array}{l}\text { Full-scale experiments } \\
\text { without } V_{10} \\
\end{array}$} \\
\hline Sturrock (1971) & - & - & - & n.a. & n.a. & $\mathrm{s}$ & $\begin{array}{l}26 \mathrm{~m} \text { high } \\
\text { building }\end{array}$ & - & - \\
\hline ASHRAE task group (1975) & - & n.a. & - & 0.3 & 8 & $\mathrm{~s}$ & $\begin{array}{l}\text { 6-storey } \\
\text { L-shape } \\
\text { building }\end{array}$ & $\begin{array}{l}\text { many } \\
\text { points }\end{array}$ & - \\
\hline Nicol (1977) & n.a. & n.a. & $0-4.72$ & n.a. & - & $\mathrm{s}$ & - & - & - \\
\hline Loveday \& Taki (1996) & $0-9.5$ & n.a. & $0-16$ & 1 & 11 & $\mathrm{~s}^{\mathrm{a}}$ & $\begin{array}{l}8 \text {-storey } \\
\text { building }\end{array}$ & $\begin{array}{l}\text { at } 6^{\text {th }} \\
\text { floor }\end{array}$ & semi urban \\
\hline $\begin{array}{l}\text { Hagishima \& Tanimoto } \\
(2003)\end{array}$ & $0.5-3$ & n.a. & $0.2-7.5$ & 0.13 & 0.6 & $\mathrm{r}$ & $\begin{array}{l}\text { 2/4-storey } \\
\text { building }{ }^{\mathrm{b}}\end{array}$ & roof & - \\
\hline \multicolumn{10}{|l|}{$\begin{array}{l}\text { Full-scale experiments } \\
\text { with } V_{10}\end{array}$} \\
\hline MoWiTT (1994) & n.a. & $0-12$ & n.a. & n.a. & n.a. & $\mathrm{s}$ & $\begin{array}{l}\text { room-sized } \\
\text { calorimeters }\end{array}$ & facade & - \\
\hline Liu \& Harris (2007) & $0-3$ & $\begin{array}{l}0- \\
16 \\
\end{array}$ & $0-9$ & 0.5 & 1 & $\mathrm{~s}$ & $\begin{array}{l}1 \text {-storey } \\
\text { building }\end{array}$ & facade & $\begin{array}{c}\text { surrounded by } \\
\text { shelterbelt }\end{array}$ \\
\hline \multicolumn{10}{|c|}{$\begin{array}{l}\text { "Smooth means that there is no other expression for different surface texture } \\
\text { b The 2-storey building is attached to a 4-storey building } \\
\text { "n.a.": not applicable } \\
\text { "-"::missing information } \\
\text { "s": smooth } \\
\text { "r": rough }\end{array}$} \\
\hline
\end{tabular}




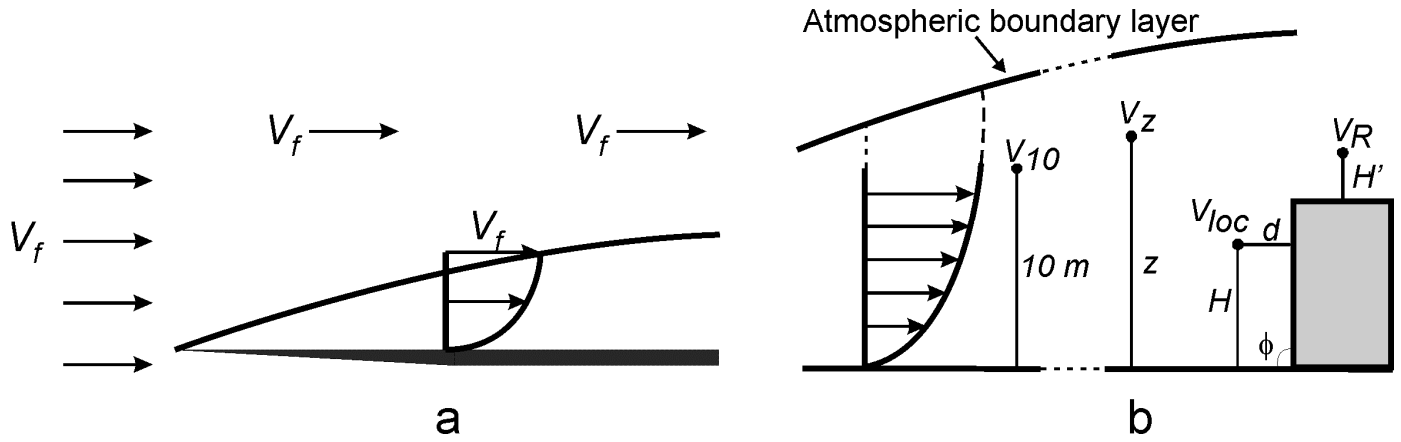

Figure 1. Different definitions of wind speed for (a) a flat plate and (b) the built environment
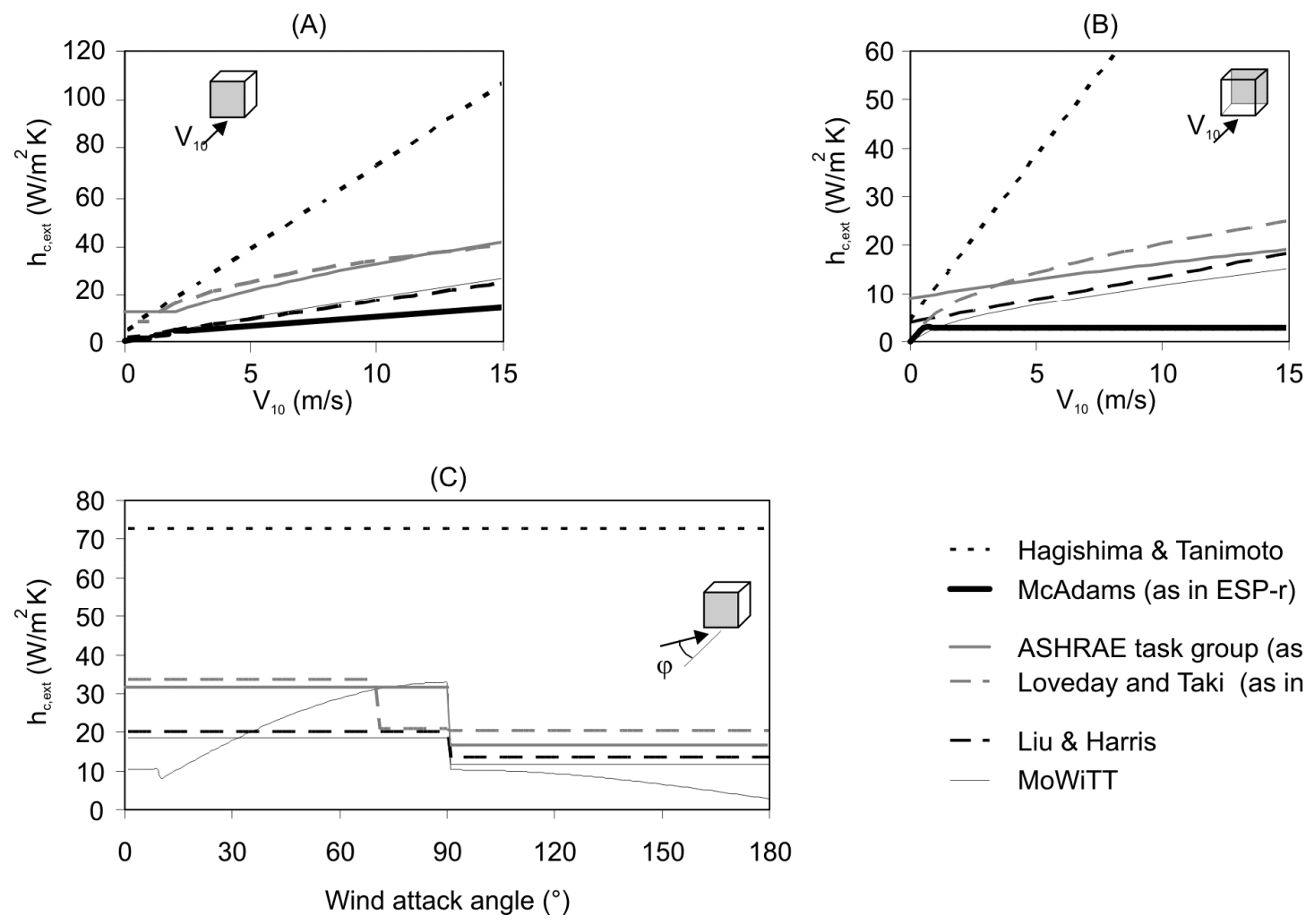
- - Hagishima \& Tanimoto
- McAdams (as in ESP-r)
- ASHRAE task group (as in ESP-r)
- - Loveday and Taki (as in ESP-r)
- - Liu \& Harris MoWiTT

Figure 2. Prediction of the convective heat transfer coefficient

for external building surfaces by different convection models. (a) Windward surfaces with wind attack angle $\varphi=$

$0^{\circ}$. (b) Leeward surfaces with wind attack angle $\varphi=180^{\circ}$. (c) Windward surfaces with $\mathrm{V}_{10}=10 \mathrm{~m} / \mathrm{s}$. 
(a)
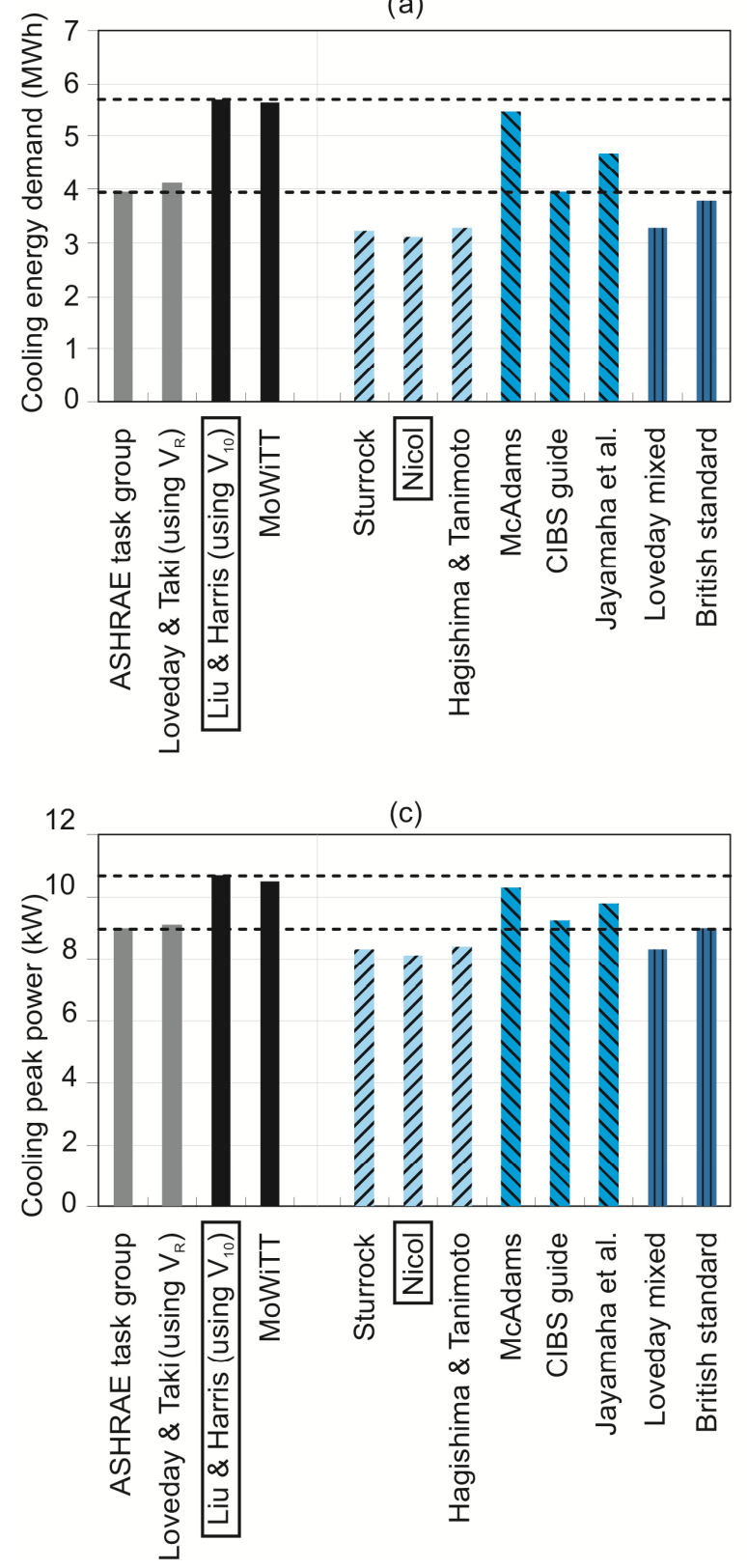

(b)

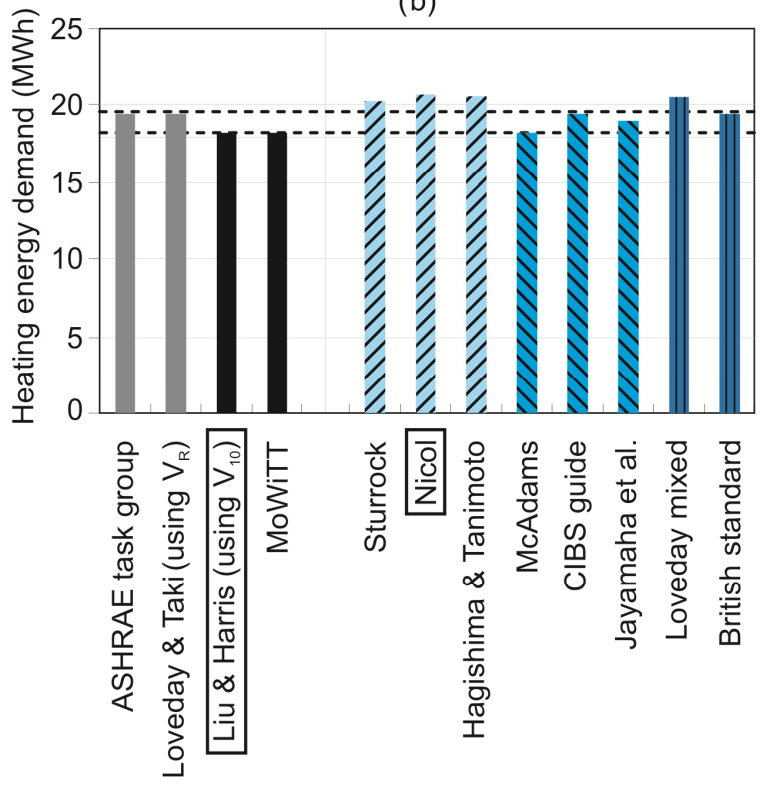

- Models for buildings with 6 to 8 storeys

- Models for buildings with 1 storey

Z Other models based on full-scale experiments

N Models based in reduced-scale experiments

III Models with few information available

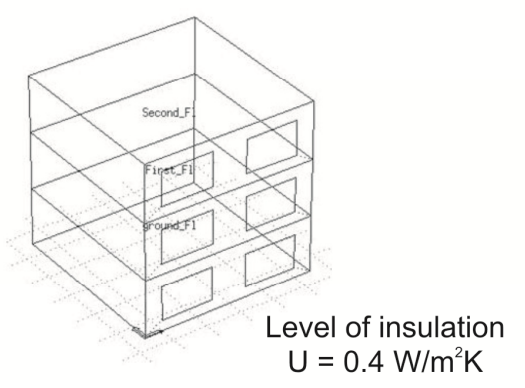

Figure 3. BES results using different convection models for the cubic building 